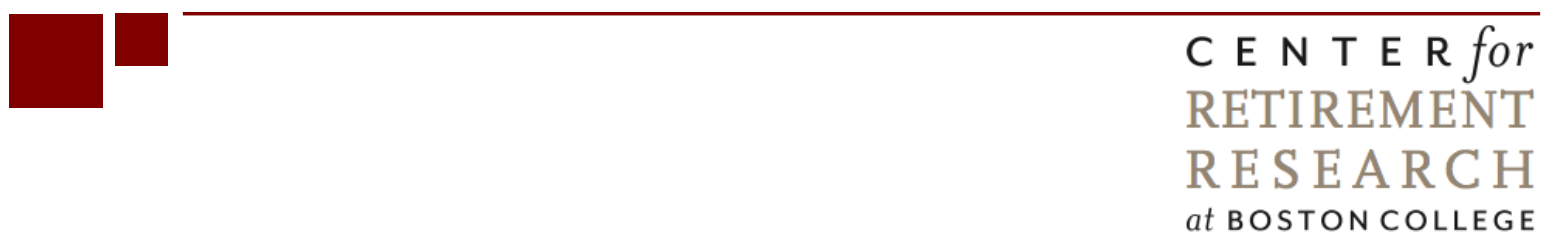

\title{
CHANGES IN LABOR FORCE PARTICIPATION OF OLDER AMERICANS AND THEIR PENSION STRUCTURES: A POLICY PERSPECTIVE
}

\author{
Frank W. Heiland and Zhe Li \\ CRR WP 2012-18 \\ LSubmitted: July 2012 \\ Released: August 2012 \\ Center for Retirement Research at Boston College \\ Hovey House \\ 140 Commonwealth Avenue \\ Chestnut Hill, MA 02467 \\ Tel: 617-552-1762 Fax: 617-552-0191 \\ http://crr.bc.edu
}

Frank W. Heiland is an associate professor of economics at Baruch College, The City University of New York. Zhe Li is an assistant professor of finance and economics at Framingham State University. The research reported here was performed pursuant to a grant from the U.S. Social Security Administration (SSA) funded as part of the Retirement Research Consortium (RRC). The opinions and conclusion expressed are solely those of the authors and do not represent the opinions or policy of SSA, any agency of the federal government, the RRC, Baruch College, The City University of New York, Framingham State University, or Boston College.

(C) 2012, by Frank W. Heiland and Zhe Li. All rights reserved. Short sections of text, not to exceed two paragraphs, may be quoted without explicit permission provided that full credit, including (C) notice, is given to the source. 


\section{About the Steven H. Sandell Grant Program}

This paper received funding from the Steven H. Sandell Grant Program for Junior Scholars in Retirement Research. Established in 1999, the Sandell program's purpose is to promote research on retirement issues by scholars in a wide variety of disciplines, including actuarial science, demography, economics, finance, gerontology, political science, psychology, public administration, public policy, sociology, social work, and statistics. The program is funded through a grant from the Social Security Administration (SSA). For more information on the Sandell program, please visit our website at: http://crr.bc.edu/opportunities/steven_h._sandell_grant_program_2.html, send e-mail to crr@bc.edu, or call Marina Tsiknis at (617) 552-1092.

\section{About the Center for Retirement Research}

The Center for Retirement Research at Boston College, part of a consortium that includes parallel centers at the University of Michigan and the National Bureau of Economic Research, was established in 1998 through a grant from the Social Security Administration. The Center's mission is to produce first-class research and forge a strong link between the academic community and decision makers in the public and private sectors around an issue of critical importance to the nation's future. To achieve this mission, the Center sponsors a wide variety of research projects, transmits new findings to a broad audience, trains new scholars, and broadens access to valuable data sources.

Center for Retirement Research at Boston College

Hovey House

140 Commonwealth Avenue

Chestnut Hill, MA 02467

phone: 617-552-1762 fax: 617-552-0191

e-mail: crr@bc.edu

crr.bc.edu

Affiliated Institutions:

The Brookings Institution

Massachusetts Institute of Technology

Syracuse University

Urban Institute 


\begin{abstract}
We investigate how the shift in private pension coverage from defined benefit (DB) to defined contribution (DC) retirement plans since the 1980s has contributed to the substantial rise in labor force participation of older Americans. We develop a life cycle model of retirement that captures important aspects of private (DB and DC) and public (Social Security Old-Age) pensions. We demonstrate how this novel framework can assist policy makers and researchers in analyzing the complex interrelations of labor supply decisions, retirement behavior, and wealth accumulation. We begin by illustrating important differences in the incentives for labor supply and retirement behavior provided by DB and DC pensions. We show that the timing of the exit from the labor force is closely tied to wealth accrual in DB plans, while wealth accrual in DC plans does not provide similar incentives for the timing of retirement. We then use the model to conduct a cohort-based simulation analysis of labor force participation for the period 1977 to 2010. The results illustrate the potential significance of the rise in employer-sponsored DC pensions in explaining the increase in labor force participation of older Americans. We estimate that, holding the share of individuals with employer-sponsored pensions constant, the shift from DB to DC pension coverage increased the labor force participation rate of workers age 60 to 64 by 4.9 percentage points (1.7 points for ages 65-69). Finally, we show that DC pension holders are more concentrated at the earliest take-up age for Social Security old-age retirement benefits and are less responsive to changes in Social Security retirement age policy than DB pension holders.
\end{abstract}




\section{Introduction}

The growing percentage of workers covered by employer-sponsored defined contribution (DC) pension plan over the past three decades — and the concurrent decline in coverage through defined benefit (DB) plans - constitutes a fundamental change in the American pension landscape. DB pension plans offer a lifetime annuity that is based on employee tenure and wages. Benefit accumulation in DB pensions typically accelerates after an extended number of years of service followed by a gradual decline towards no accrual around a set "normal" retirement age (frequently age 62). Employer-sponsored DC plans are individual retirement accounts funded through tax-deductible contributions by the worker (frequently matched in part or fully by the employer). In DC pensions, contributions and returns accumulate independently of job tenure and pension accruals are unaffected by individuals' retirement decision.

In this paper, we investigate the differing incentives provided by DB and DC pensions for individuals' labor supply and retirement behavior and assess to what extent the shift from DB to DC pension coverage over the past three decades may have contributed to the rising labor force participation of Americans around traditional retirement ages (ages 60 to 64). To conduct the conceptual and empirical analysis, we develop and estimate a life cycle model of retirement that incorporates important characteristics of DB and DC pensions and accounts for the incentives provided by Social Security’s Old-Age retirement benefit program.

Background. Labor force participation by older men has increased noticeably over the past two decades, reversing a multidecade decline. As shown in Figure 1-A, the participation rate of men aged 60 to 64 increased from 54.4 percent in 1988 to 60 percent in 2010. Males age 65 and older also experienced a significant increase in labor market attachment: 22.8 percent of men in this age group participated in the labor force in 2010, compared to 16.8 percent in 1994 . This is in stark contrast to the participation trend of male workers below traditional retirement ages. As shown in Figure 1-A, participation rates of men age 45-54 and 55-69 have been flat or declining over this period. The labor market attachment of older women also has increased dramatically since the late 1980s, following an extended period of stable attachment at relatively low levels (see Figure 1-B). ${ }^{1}$

\footnotetext{
${ }^{1}$ Participation among women ages 60 to 64 increased from 33.2 percent in 1987 to 50.7 percent in 2011 (see Figure 1-B). Female participation at age 65 and above has risen from 7.4 percent to 13.8 percent over the same period.
} 
While the labor force participation of older Americans has risen, the way workers save for their retirement has fundamentally changed (e.g., Gruber and Wise 2005). The share of workers with defined contribution DC pension plans has increased gradually since the 1980s at the expense of traditional defined benefit DB plans. Based on Survey of Consumer Finances data, the share of all males with private pension coverage that rely solely on a DB plan dropped from 31 percent to 16 percent over the period 1992-2007, and the share of males with only a DC plan increased from 47 percent to 63 percent (see Figure 2). ${ }^{2}$ The pension coverage for females displays a similar trend

Using data from the Survey of Income and Program Participation (SIPP), we can document the shift in type of pension (DB vs. DC) and coverage (plan vs. no plan) across cohorts (see Figure 3). We estimate that in the 1925 birth cohort — individuals attaining age 60 in 1985 less than 5.3 percent of workers age 50 to 59 had a DC pension as primary plan with their current employment, while 52.9 percent had a DB plan and 41.8 percent had no plan. ${ }^{3}$ In the birth cohort of 1959 - individuals attaining age 60 in 2009 - 23.8 percent of workers age 50 to 59 had a DC plan at their current job, 28.5 percent had a DB plan, and 47.7 percent had no plan.

The shift in employer-sponsored retirement plans from DB to DC pensions currently under way has been primarily attributed to legislative changes, demand-side factors, and occupational trends. The availability of individual accounts began in the 1980s after the Revenue Act of 1978 allowed workers to make (voluntary) tax-deductible contributions to employer-sponsored retirement plans. Tax laws enacted in the 1980s, including the Tax Equity and Fiscal Responsibility Act of 1982 and the Tax Reform Act of 1986, made DB plans more costly to maintain and all but halted the adoption of DB plans by new business since then (Rajnes 2002; Munnell and Sundén 2004). In recent years, many private-sector employers have moved to freeze their DB plans entirely (Munnell et al. 2006).

Unlike for men, however, the participation rate of women at younger ages has been on a secular rise (e.g., Goldin 1994).

${ }^{2}$ About 20 percent of males had dual coverage of DB and DC pensions. This share held steady between 1992 and 2007.

${ }^{3}$ To construct Figure 4, we combined data from various waves of the SIPP ("Retirement Expectation and Pension Plan Coverage Topical Module") that ask about private pension availability and participation on the current job (1984 wave 4 to 2009 wave 7). The results refer to the main plan (if any) with the current job. Individual sampling weights are applied as the SIPP (increasingly) oversamples low income households. Our estimates are comparable to those reported in Poterba et al. $(2006,2007)$. 
The greater flexibility and transparency of DC plans (self-directed and portable across jobs) has also been cited as a reason for their popularity (Munnell and Soto 2007; Aaronson and Coronado 2005). Furthermore, the change in the occupational structure from manufacturing to service employment provided an important catalyst for the rise in the share of jobs with DC plans. Evidence suggests that half of the decline in DB coverage may be due to occupational trends and half to plan substitutions by employers (Gustman and Steinmeier 1992; Ippolito and Thompson 2000).

Contribution. Pension wealth in DB plans is a function of an individual's earnings history and years of service. DB pensions are usually structured to encourage workers not only to remain with the firm to take advantage of the large pension accruals later in the career, but also to retire by a particular age. Typically, that is achieved by providing a slow accumulation of benefits in the early years on the job, acceleration or jumps after many years of tenure, followed by a gradual decline towards no accrual around the "normal" retirement age set by the plan (frequently age 62). ${ }^{4}$ DC pensions operate differently: Contributions and returns accumulate in a portable individual retirement account and pension accruals are unaffected by the worker's retirement decision.

The design of DC pensions provides an important, direct incentive for workers to remain employed. In most DC plans, such as 401(k) and 403(b) plans, employers make contributions to match some or all of the employee's contributions. These employer matches are a type of employee benefit and increase the rate of return on labor supplied. As a consequence, workers with plans that provide matching may supply more labor, including through staying in the labor market longer in order to benefit from the employers' additional investment in their retirement.

In this paper, we investigate the incentives provided by DB and DC pensions and assess how the change in occupation pension coverage from DB to DC may have affected the labor supply behavior of older workers. In light of the differences between DB and DC pension plans discussed above and previous evidence on the labor supply of individuals with DB and DC pensions, we conjecture that the shift to DC pensions that began in the 1980s contributed to the rise in labor force participation at traditional retirement ages (age 60-64). We are then

\footnotetext{
${ }^{4}$ We restrict the use of the term "normal retirement age" to the context of DB plans. In contrast, we refer to the age at which beneficiaries can claim their full Social Security benefits as "Full Retirement Age" (or "FRA").
} 
particularly interested in assessing how much of the observed rise in labor force participation may be attributed to this phenomenon.

A number of conceptual and empirical studies have analyzed DB and DC pensions in the context of retirement behavior. Kotlikoff and Wise (1989), Stock and Wise (1990a, 1990b), Lumsdaine, Stock and Wise (1992), Samwick (1998), and Coile and Gruber (2000) show that the structure of DB pensions provides a powerful incentive to leave the job and retire before the plan's normal retirement age. French (2005), using a structural (life cycle) framework similar to the one adopted in this paper, shows that DB pensions are a key element of the high observed job exit rates at ages 62 and 65.

Friedberg and Webb (2005) and Munnell, Cahill, and Jivan (2003) provide evidence that employees with DC pensions retire later than those covered by DB plans. Specifically, Friedberg and Webb (2005) estimate that the absence of age-related incentives in DC plans leads workers to retire almost two years later than those in DB plans. Munnell, Cahill, and Jivan (2003) estimate that workers covered by a DB plan retire fifteen months earlier than those covered by a 401(k) plan.

Research on the impact of the changing private pension landscape on the trend in labor force participation of older workers has been limited. The few studies that exist on the rising labor force attachment of older worker focus on other explanations, most notably changes in the retirement incentives provided by Social Security's old-age program.

Mastrobuoni (2009) links rising labor supply to the increases in the FRA (the age at which individuals can claim their full Social Security benefits) since 1999. However, this development cannot explain the rising labor force participation of Americans reaching retirement age before 1999 (those born prior to 1938) shown in Figures 1a and 1b, as they all were subject to an FRA of age 65 .

Blau and Goodstein (2010) more broadly examine the effects of changes in Social Security policy on the labor force participation of older men. They estimate that increases in the FRA and the Delayed Retirement Credit (a credit for Social Security benefit take-up after FRA that increased from 3 to 8 percent per year across birth cohorts 1924-1943) explain one quarter to one half of the recent increase in the labor force participation (1.2 to 2.4 percentage points for men aged 55-69). Rising labor supply of married women and changes in the educational composition of the older male population are contributing factors as well. Their regression analysis accounts 
for pension coverage and type and finds that DC pension coverage has a small positive effect on labor force participation, but statistically insignificantly different from zero. However, the authors refrain from drawing conclusions from this result regarding the contribution of the changes in the private pension structure to the trend in male labor force participation, acknowledging that the incentives would need to be analyzed more carefully.

In earlier related work, Schirle (2008) estimates that husbands' responses to increases in wives' labor force participation explain about a quarter of the increase in the labor force participation of married men age 55 to 64 between 1994 and 2005. The paper does not provide a reduced-form analysis that permits testing for fundamental factors such as pension type. ${ }^{5}$

One objective of the present work is to quantify the potential contribution of the change in pension structure to the observed increases in the labor force participation of older Americans since the 1980s. Drawing on previous conceptual approaches and results, we construct and estimate a life cycle model of labor supply, retirement, and savings behavior, in which the agents can receive retirement income from Social Security Old-Age benefits and from an employersponsored DB or (tax-deferred) DC pension. Individuals choose their labor supply, consumption, and contribution to a DC pension account and a regular after-tax savings account, and whether to claim Social Security old-age benefits.

The life cycle retirement framework is useful to analyze the complex effects of changing fundamentals including policies and institutional settings on labor supply, benefit take-up, and wealth accumulation (see Gustman and Steinmeier 1986; Rust and Phelan 1997). Previous models have focused on DB pensions and older cohorts (e.g., French 2005). By incorporating DC pensions, we create a framework that can be applied more broadly across cohorts, complementing empirical approaches to the analysis of labor force participation trends (e.g., Blau and Goodstein 2010).

We show that wealth accrual in DB plans is closely tied to the timing of exit from the labor force, while the incentives by DC plans are neutral with respect to the timing of retirement. The model is estimated and simulated for cohorts subject to different pension coverage rates and

\footnotetext{
${ }^{5}$ The author dismisses a shift in pension structure as a viable explanation, citing evidence that the "percentage of workers participating in defined-benefit plans was $21 \%$ in both 1999 and 2004" (p. 569). It is unclear why the year 1999 was selected in place of an earlier year such as 1994, which would have been more consistent with the period of the main analysis and likely would have shown a shift from DB to DC over this time period. Also, the relevant DB participation rates are those of older workers (e.g., age 55 to 64), rather than the rates for employees of all ages mentioned in the paper.
} 
distributions of pension type. Calculating participation rates in the period 1977-2010, we find that in the absence of DC pension plans the labor force participation rate of workers age 60-64 would have been as much as 4.9 percentage points lower (1.7 points for ages 65-69), accounting for the declining proportion of individuals with employer-sponsored pension. Finally, we show how the type of pension affects how Social Security policy, namely increases in the Delayed Retirement Credit and the Full Retirement Age, effect labor supply and Social Security benefit take-up. 


\section{MODEL}

Basic Setup. Consider an individual seeking to maximize his expected lifetime utility at age (or equivalently, year) $\mathrm{t}, \mathrm{t}=1,2, \ldots, \mathrm{T}+1$. Each period that she lives, the individual receives utility, $U_{t}$, from consumption, $C_{t}$, hours worked, $H_{t}$, and health (or medical) status, $M_{t}$. When she dies, she values bequests of assets, $A_{t}$, according to a bequest function $b\left(A_{t}\right)$. Let $F_{t}$ denote the probability of being alive through period t. Then the preferences can be written as follows;

$$
U\left(C_{t}, H_{t}, M_{t}\right)+E_{t}\left[\sum_{j=t+1}^{T+1} \beta^{j}\left(F_{j} U\left(C_{j}, H_{j}, M_{j}\right)+\left(F_{j-1}-F_{j}\right) b\left(A_{j}\right)\right)\right]
$$

where $\beta$ is the discount factor.

The within-period utility function is of the form:

$$
U\left(C_{t}, H_{t}, M_{t}\right)=\frac{1}{1-\gamma}\left(C_{t}^{v}\left(L-H_{t}-\theta_{p} P_{t}-\phi I\left\{M_{t}=\text { poor }\right\}\right)^{1-v}\right)^{1-\gamma}
$$

where $\gamma$ measures the coefficient of relative risk aversion, and $v$ the consumption weight. The per-period time endowment is $L$ and the quantity of leisure consumed is $L-H_{t}-\theta_{p} P_{t}-\phi I\left\{M_{t}=\right.$ poor $\}$. The $0-1$ indicator $I\{M=$ poor $\}$ is equal to 1 when the health status is poor and 0 otherwise, and $\phi$ represents the hours of leisure lost in poor health.

Participation in the labor force is denoted by $P_{t}$, a $\{0,1\}$ indicator equal to 0 when hours worked, $H_{t}$, equals zero. The fixed cost of work, $\theta_{p}$, is measured in hours worked per year.

Retirement is assumed to be linked to the labor force participation decision, and workers can reenter the labor force.

The bequest function s of the form:

$$
b\left(A_{t}\right)=\theta_{B} \frac{\left(A_{t}+K\right)^{(1-\gamma) v}}{1-\gamma}
$$


where $\theta_{B}$ is the bequest weight, and $K$ determines the curvature of the bequest function. If $K=0$ there is infinite disutility of leaving non-positive bequests. If $K>0$, the utility of a zero bequest is finite.

The value of $F_{t}$ is given by $F_{t}=\exp \left(-\sum_{j=0}^{t} \vartheta_{j}\right)$

where $\vartheta_{j}>0$ is the single period hazard rate for period j with $\vartheta_{T+1}=\infty$. In practice, the individual's annual mortality rates are calibrated to match those for the U.S. population.

We assume that there are three different pensions: Social Security (SS), defined benefit (DB) plans and tax-deferred defined contribution (DC) plans. In addition to choosing hours and consumption, eligible individuals can choose how much to save in the DC pension account and when to start collecting their Social Security benefits.

Let the indicator variable $D C_{t} \in\{0,1\}$ equal one if the individual has an option of DC account, and savings in DC account, $S_{t}>0$, only if $D C_{t}=1$. At each age above 62, the individual can choose whether to apply for Social Security benefits; the indicator variable $B_{t} \in\{0,1\}$ equals to one if the individual has applied for Social Security benefits.

The individual maximizes equation (1) by making the contingency choices $\left\{C_{j}, H_{j}, S_{j}, B_{j}\right\}_{j=t}^{T+1}$, subject to the following equations: wage determination equations (4) and (5), asset accumulation equations (6) and (7), and a health determination equation (8).

Given the objective function, individuals face several constraints. The logarithm of wages at time $\mathrm{t}, \ln W_{t}$, is a function of hours worked, age, and health status, plus an autoregressive component of wages $A R_{t}$ :

$\ln W_{t}=\alpha \ln H_{t}+W\left(M_{t}, t\right)+A R_{t}$. 
The coefficient $\alpha$ parameterizes the part-time wage penalty, and the function $W\left(M_{t}, t\right)$ is the wage profile estimated from data. The autoregressive component of wages has a correlation coefficient $\rho$ and a normally distributed innovation $\eta_{t}$ :

$$
A R_{t}=\rho A R_{t-1}+\eta_{t}, \eta_{t} \rightarrow N\left(0, \sigma_{\eta}^{2}\right)
$$

By assumption, the worker knows the autoregressive component of wages $\left(A R_{t-1}\right)$ at time $t-1$, but only knows the distribution of the innovation in next period's wage $\left(\sigma_{\eta}\right)$.

The wealth would accumulate in the following ways:

$$
\begin{aligned}
& D C_{t+1}=D C_{t}(1+r)+S_{t}-w d r_{t} \\
& A_{t+1}=A_{t}+Y\left(r A_{t}+W_{t} H_{t}-S_{t}+w d r_{t} \times(1-p n l) I\{t<60\}+D B_{t}, \tau\right)+\left(B_{t} \times s S_{t}\right)-C_{t}
\end{aligned}
$$

Equation (6) describes the pretax wealth accumulation in DC pension account, where $D C_{t}$ denotes the DC account balance, $r$ is the determinant investment return, $S_{t}$ is the pretax savings amount into the DC account, and $w d r_{t}$ is the withdrawal (subject to penalty before retirement age). When the agent dies, $D C_{t+1}$ equals to zero. Equation (7) denotes the wealth in the regular after-tax saving account. $Y\left(r A_{t}+W_{t} H_{t}-S_{t}+w d r_{t} \times(1-p n l) I\{t<60\}+D B_{t}, \tau\right)$ is the level of post-tax income, where $W_{t}$ is the stochastic wage rate, pnl is the penalty on early withdrawal in the DC account (before age 60), ${ }^{6} D B_{t}$ denotes DB pension benefits, and $\tau$ represents the actual progressive tax structure. $\left(B_{t} \times S S_{t}\right)$ denotes the Social Security payments. Individuals cannot draw Social Security benefits until age 62, and the age of DB pension benefit receipt is set to age 60.

\footnotetext{
${ }^{6}$ Currently, the age at which individuals can withdraw retirement funds without penalty in a regular IRA is $591 / 2$.
} 
In addition, next year's health status, $\operatorname{prob}\left(M_{t+1} \mid M_{t}, t+1\right)$, depends on current health status and age. Health status follows a two-state transition matrix at each age with a typical element of the following form:

$$
\pi_{\text {good }, p o o r, t+1}=\operatorname{prob}\left(M_{t+1}=\operatorname{good} \mid M_{t}=\text { poor }, t+1\right) \text {. }
$$

Pensions. We assume that the pension system consists of three different plans: a public pension plan, Social Security, an employer-sponsored defined benefit pension, and an employersponsored defined contribution pension. Social Security is available to everyone, while the availability of DB and DC plans depends on the employer. Generally speaking, individuals who have longer working experience and earn higher wages are more likely to have employersponsored pensions.

Social Security. Social Security benefits depend on the Average Indexed Monthly Earnings, or $A I M E_{t}$, which is average earnings in the 35 highest earnings years. AIME is converted into the Primary Insurance Amount (PIA). Individuals are ineligible for Social Security benefits before age 62, the Early Retirement Age (ERA). Upon application for benefits the individual typically receives them until death. The amounts of benefits depend on a progressive function of AIME and the year the individual starts drawing benefits. For every year the individual applies for benefits prior to reaching her Full Retirement Age (FRA) benefits are reduced in accordance with the early retirement rules of Social Security (see Myers 1993). For every year benefit take-up is delayed past FRA until age 70 benefits rise, in accordance with the Delayed Retirement Credit (DRC). For example, the FRA of Americans born before 1938 is exact age 65 and take-up before that reduces the payout by 6.67 percent per year. For every year between ages 65 and 70 that benefit application is delayed, benefits rise between 3 percent and 6.5 percent, depending on the cohort. While the adjustments for early benefit take-up are approximately actuarially fair for average mortality individuals, the rates of the DRC are considered too low to be actuarially fair from the perspective of average Americans (e.g., Myers and Schobel 1990 and Heiland and Yin 2012), suggesting that there is an incentive to draw 
benefits by age 65. A detailed description of the computation of AIME and PIA is provided in the Technical Appendix A.1.

The rules governing early benefits allow for the adjustment of the penalty rate as a result of benefit withholding due to earnings above the Social Security Earnings Test limits (see BenítezSilva and Heiland 2007 and 2008). Until its abolition in 2000, there was also a post-FRA Earnings Test. The Earnings Test determines the maximum earnings that do not result in a benefit reduction for individuals who have claimed retirement benefits before the FRA. Individuals who continue (including re-enter) employment after claiming benefits early and who earn less than the earnings limit receive benefits at the reduced rate. Those with earnings above the limit, on the other hand, may not receive all checks from Social Security, as some benefits will be withheld. Benefits withheld before FRA increase the benefit payout after FRA, when the penalty rate is adjusted. ${ }^{7}$ Among the 1,543,000 Americans who claimed early benefits in 2010, only 103,600 (6.71 percent) had any benefit withholding due to earnings (SSA-S, 2011, Table 6.B.5.1). Given the relatively small fraction of beneficiaries affected by this rule and the considerable complexity of modeling this aspect (see Benítez-Silva and Heiland 2007), we abstract from benefit withholding and subsequent recalculation of the payout rate here.

Defined Benefit Pensions. Defined benefit pensions are similar to Social Security old-age benefits in two aspects. First, pension wealth is illiquid until some "early retirement age," which is usually age 55, 60 or 62 , depending on the pension plan. For simplicity, we assume that DB pension wealth is illiquid until age 60. Second, DB pension benefits depend on the individual's work history. Because of this, DB pension benefits are assumed to be a function of AIME, just like Social Security benefits.

DB pensions differ from Social Security in that they provide age-specific incentives to leave the labor force. DB pension plans are typically structured in a way that encourages a worker to remain at a firm until the early retirement age (Ippolito 1997; Friedberg and Owyang 2005) and to leave the firm no later than the normal retirement age (usually 62 or 65). DB pension benefits depend on age and years of company service, as well as the highest annual earnings at the firm

\footnotetext{
${ }^{7}$ Benítez-Silva and Heiland (2007) provide additional detail on the rules governing benefit withholding and a numeric example of the streams of income resulting from these incentives. There are also other strategies for early claimers to reduce or potentially entirely undo the penalty effective at FRA (see Benítez-Silva and Heiland 2007; Munnell et al. 2009).
} 
(usually the average of the five highest earnings years). The pension accrual rates are generally higher for individuals in their 50s and lower at other ages. The pension formula component increases in age up to normal retirement age and is flat thereafter, resulting in a reduction in the present value of pension benefits when retirement is delayed past the normal retirement age, ${ }^{8}$ so this feature generates an incentive to leave the firm by the normal retirement age. The setup of the DB pension benefits is described in the Technical Appendix A.2.

Defined Contribution Pensions. DC pensions are individual retirement savings accounts. These accounts differ from regular savings accounts in two important ways: (i) the contributions to the accounts and the investment earnings are tax-deferred until retirement and (ii) preretirement withdrawal from the accounts is subject to penalties. ${ }^{9}$ We assume that the investment strategies in DC accounts and regular savings accounts are the same, with a rate of return of $\mathrm{r}^{10}$ In addition, we assume that half of the employers offering DC pensions make some contributions to match the individuals' own savings. The matching rate is set at 50 percent, up to 10 percent of the salary. ${ }^{11}$

Model Solution. The optimal decisions at each period, $\left\{C_{t}, H_{t}, S_{t}, B_{t}\right\}$, depend on the state variables $X_{t}=\left(A_{t}, W_{t}, D C_{t}, B_{t}, M_{t}, A I M E_{t}\right)$, preferences $\theta=\left(\beta, \gamma, v, \theta_{P}, \theta_{B}, \phi, L\right)$, and the parameters that determine the data generating process denoted as:

$$
\begin{gathered}
\chi= \\
\left(r, \alpha, \rho, \sigma_{\eta}, \tau, W\left(M_{t}, t\right),\left\{F_{t}\right\}_{t=25}^{T},\left\{p r o b\left(M_{t+1} \mid M_{t}, t\right)\right\}_{t=25}^{T},\left\{D B_{t}\right\}_{t=25}^{T},\left\{s s_{t}\right\}_{t=25}^{T},\left\{y s_{t}\right\}_{t=25}^{T}\right) .
\end{gathered}
$$

The value function is the solution to

\footnotetext{
${ }^{8}$ Although delaying benefit receipt causes slightly higher annual benefits (because years of service at the firm have increased), the individual will receive benefits for fewer years.

${ }^{9}$ The age at which the withdrawal is not subject to penalty is currently 59 and 6 months for IRAs.

${ }^{10}$ Considering the size of the problem, we will abstract from investment choices. A detailed analysis of the asset allocation and location decisions (in taxable and tax-deferred accounts) can be found in $\operatorname{Li}(2010)$.

${ }^{11}$ Although contribution amount varies from one employer to another, according to Survey of Consumer Finances (1992-2007), the share of employers with DC pensions that offer a contribution is about 63 percent, and the average matching rate of the employer contribution is about 53 percent.
} 


$$
\begin{gathered}
V_{t}\left(X_{t}\right)=\max _{\left\{C_{t}, H_{t}, S_{t}, B_{t}\right\}}\left\{U\left(C_{t}, H_{t}, M_{t}\right)+e^{-\vartheta_{t+1} \beta}\right. \\
\times \sum_{M \in\{\text { good,bad }\}} \int V_{t+1}\left(X_{t+1}\right) d F\left(W_{t+1} \mid W_{t}, M_{t+1}, t\right) \operatorname{prob}\left(M_{t+1} \mid M_{t}, t\right) \\
\left.+\left(1-e^{-\vartheta_{t+1}}\right) \beta b\left(A_{t+1}\right)\right\}
\end{gathered}
$$

The decision rules are solved numerically, starting at period $\mathrm{T}$ and working backwards. Since there is no closed form solution to the problem, the state variables are discretized into a finite number of points on a grid and the value function is evaluated at those points. We use linear interpolation within the grid and extrapolation outside of the grid to evaluate the value function points that were not directly computed. We integrate the value function with respect to the innovation in the wage using quadrature. Because the fixed cost of work and the Social Security benefit application decision mean that the value function need not be globally concave, we also discretize the consumption and labor supply decisions and use a grid search technique to find the optimal consumption and hours of work. The grids seem to produce reasonable approximation. The numerical algorithm is explained in the Technical Appendix A.3.

\section{Estimation}

We will recover the structural parameters in the theoretical model using the method of simulated moments (MSM). Because it would be too computational burdensome to estimate all parameters simultaneously, we use a two-step strategy. In the first step, we estimate some elements of the parameter set and calibrate others to get the data generating process for the state variables. In the second step, we use the estimated data generating process for state variables to simulate life cycle profiles for a large number of hypothetical individuals. The goal is to find the preference parameters that generate simulated profiles that match the data. The MSM technique is described in the following subsection. Section 3.2 describes the estimation of the data generating process and the calibration. 
Estimation of Preference Parameters. The method of simulated moments (MSM) matches the Social Security claim age distribution to the corresponding moments of the same variables in the simulated sample. The procedure is done using standard GMM techniques.

The objective is to find a vector of preferences $\theta \in \Theta$ that simulates a distribution such that it fits the data best. We assume $\Theta \subset \mathbb{R}^{5}$ where $\Theta$ is a compact set. We assume that households start off their retirement savings with an initial wealth level, and for each set of parameters we compute the policy rules that solve the dynamic problem and then use these rules to generate simulated decision rules over the life cycle. Then at each iteration we construct a measure of distance between the observed and simulated moments, namely the Social Security benefit claiming age distribution from 62 to 67 (see Figure 4).

Thus, there are $\mathrm{J}=6$ moments and $\mathrm{N}=5$ parameters in the estimation. Let the parameter set be denoted by $\theta$, and the observation of each moment $j$ for individual $i$ by $\zeta_{i}^{j}, j=1, \ldots, J$. We seek to estimate the model from the following moment conditions:

$$
\mathrm{E}\left[\zeta_{\mathrm{i}}^{\mathrm{j}}-\hat{\zeta}^{\mathrm{j}}\left(\theta_{0}\right)\right]=0
$$

where $\theta_{0}$ is the true parameter vector, and $\hat{\zeta}^{\mathrm{j}}\left(\theta_{0}\right)$ is the predicted counterpart. Therefore the estimation procedure is then a MSM (see details in Pakes and Pollard 1989 and Duffie and Singleton 1993) that minimizes over $\theta$ :

$$
S(\theta)=g(\theta)^{\prime} \operatorname{Wg}(\theta)
$$

where $g(\theta)=\left[g_{1}(\theta), \ldots, g_{J}(\theta)\right]$ with the jth element as $g_{j}(\theta)=\frac{1}{I_{j}} \sum_{i=1}^{I_{j}} \zeta_{i}^{j}-\hat{\zeta}^{j}(\theta)$, where $I_{j}$ is the number of observations for the jth moment. $W$ in equation (10) is a positive definite weighting matrix, which can be chosen so that the MSM estimator $\tilde{\theta}=\operatorname{argmin}[S(\theta)]$ is both consistent and asymptotically normally distributed (Gourinchas and Parker 2002; Cagetti 2003).

In our application, we simulate life cycle working, consumption, and saving profiles by generating a sequence of 20,000 income processes and income uncertainty over 70 years, and compute the Social Security benefit claim age distribution from age 62 to 67 . Once the 
optimum is found, the asymptotic standard errors are evaluated numerically using the gradient of the moment vector. Considering the size of this problem, parallel programming techniques as implemented in Message Passing Interface (MPI) are applied to make the problem computationally feasible. The extensive explanation of the MSM estimator, the derivation of the standard error, and the procedure of parallel programming are provided in the Technical Appendices A.3 and A.4.

Calibration. In order to solve for the optimal decisions, we calibrate the parameters that determine the individual time and bequest preference, the data generating process annual wages, retirement savings rules and the returns on investment. Table 1 describes the values of parameters used in the simulation.

Some preference parameters are calibrated rather than estimated. For instance, the discount factor, $\beta$, is set at 0.96 and bequest weight, $\theta_{B}$, at 0.1 . The curvature of the bequest function, $K$, is equal to $\$ 500,000$, the same value as in De Hardi (2004).

The parameters in the wage equation are determined as following. The variance of the innovation in wages and the autoregressive coefficient of wages are set as $\left(\sigma_{\eta}^{2}, \rho\right)=(0.0141$, 0.977). The values are estimated by French (2005) using the Panel Study of Income Dynamics (PSID) for the years 1968-1997. The coefficient $\alpha$, which parameterizes the part-time wage penalty, is set at 0.415, in keeping with values reported in Gustman and Steinmeier (1986) and Aaronson and French (2004). It implies that part-time workers (who work 1000 hours per year) earn 25 percent less per hour than full time (2000 hours per year) workers. French (2005) suggests that controlling for the fact that part-time workers make less per hour than full-time workers eliminates most of the wage declines after age 60.

For much of our analysis we use a pre-tax interest rate of 3.04 percent, applied to both pension and non-pension savings. This rate is the average real return for long-term treasury bonds from 1977 to 2011 (see Table 2) as discussed below in more detail. ${ }^{12}$ Survival probabilities by health status are derived from values used in French (2005) calculated from

\footnotetext{
${ }^{12}$ This assumes that individuals invest in treasury securities only. In reality the wealth may be invested in equities with greater (risk-adjusted) yields than fixed income securities. A greater rate of return would result in greater DC pension wealth, thus increasing the retirement wealth for DC pension owners.
} 
health indicators from the PSID (1968-1997) and mortality statistics from the National Center for Health Statistics (entire population).

Regarding the defined contribution accounts, we assume that each individual can contribute up to 20 percent of her salary annually (q). When employers make contributions into individual retirement accounts, the baseline matching rate, $\mathrm{m}$, is 50 percent and up to 10 percent (limit) of the employees' salaries. Namely, an employee who makes $\$ 1$ contribution into the retirement savings account can get a 50 cents match from the employer, as long as the contribution is below 10 percent of her annual salary. If the individual withdraws from the pension before age 59 and 6 months, the amount withdrawn is subject to a 10 percent penalty (pnl). ${ }^{13}$

When simulating cohort labor supply, we incorporate important characteristics of the economic environment in each period, such as Social Security (policy) parameters (payroll taxes, maximum taxable earnings, benefit adjustments for early take-up), the income tax structure, and labor market conditions (pension coverage, unemployment). The details of the real time factors are discussion in the next section.

\section{Data and Simulation}

Data. To estimate the preference parameters of the model as explained in Section 3.1, we employ data on the Social Security claiming age distribution for male beneficiaries born in 1917. We select this cohort for estimation because it is the starting cohort in our labor supply analysis since its members are unlikely to have DC pension plans. Information on age at Social Security benefit take-up is obtained from the 2001 wave of Social Security's 1 percent Master Beneficiary Microdata (MBM). These data are a public-use 1 percent simple random sample of all beneficiaries in December 2001. The distribution of claimants in the 1917 male cohort across ages 62 and 67 used in the estimation procedure is shown in Figure $4 .^{14}$

To study the role of pension benefit type on labor force participation of older workers, we conduct a comprehensive simulation of cohort labor supply behavior using the framework

\footnotetext{
${ }^{13}$ To discourage the use of retirement funds for purposes other than retirement, IRS law imposes an additional 10 percent tax on certain early distributions of these funds. Early distributions are those one receives from an IRA before reaching age 59 and 6 months (see http:/www.irs.gov/taxtopics/tc558.html).

${ }^{14}$ Using subsequent MBA data, we investigated the potential survivorship bias in this sample. No evidence of a significant bias was found.
} 
developed above. We simulate the model for birth cohorts 1917 to 1965 (ages 25 to 94). Individuals born in 1917 - the cohort that we estimate the preference parameters for-are selected as the initial cohort because tax-deferred DC pension plans only started to became available after this cohort had already attained retirement age.

As discussed above, the availability of individual accounts began in the 1980s after the Revenue Act of 1978 allowed workers to make pre-tax contributions to employer-sponsored retirement plans. Based on Survey of Income and Program Participation (SIPP) data, we estimate that less than 5 percent of individuals age 50 to 59 had a DC plan in the 1923 birth cohort (see Figure 3). Consequently, we assume that individuals in this cohort (and earlier cohorts) do not have DC plans. All subsequent cohorts are assumed to have the same preferences as the 1917 birth cohort but face a gradually increasing availability of DC pension plans as shown in Figure 3 and explained in detail in the next section.

To account for variation in important economic factors, in addition to private pension structure, we incorporate difference in income and Social Security payroll taxation and unemployment observed across time (life cycles of individuals from different cohorts). Table 2 provides time series data on hourly wages in manufacturing (in 2010 dollars), the Social Security payroll tax rate, the unemployment rate, the inflation rate and the nominal market interest rate on 10 year constant-maturity U.S. treasuries since 1940. Historic individual federal income tax rate data are too detailed to list here but can be found online (e.g., on the website of the Tax Foundation at http://taxfoundation.org/).

In our comprehensive cohort simulation exercise, we assume a real rate of return, $r$, of 3.04 percent, based on the average real yield of 10 year constant maturity treasuries over the 19772011 period, calculated from the data in Table 2. This value is roughly consistent with rates used by the Actuarial Office of Social Security. In supplementary analysis, we also use the actual annual rates to investigate the sensitivity to differences in yields across individuals from different cohorts.

We implement the actual limits for the maximum taxable earnings in a year under Social Security (nominal values shown in Table 2). In the main cohort analysis, we specify a Delayed Retirement Credit (DRC) of 3 percent per year and a Full Retirement Age (FRA) of age 65. FRA 65 is consistent with the take-up rules for beneficiaries born up to 1937—attaining FRA in 
2002. Social Security benefits are reduced at a rate of 6.67 percent for each year of advanced take-up, up to the early eligibility age of $62 .{ }^{15}$

Our baseline cohort simulation results are net of any effects of the increases in the DRC and the FRA. We investigate these factors separately. For cohorts 1917-1924 benefits increase by 3 percent per year of delayed take-up until age 70 after which there is no incentive to delay further. For subsequent cohorts of beneficiaries, the DRC rate increases by 0.5 percentage points every two years, up to the 1943 cohort for which the DRC is 8 percent per year. The FRA increased gradually from 65 to 66 for individuals born after 1937. (See Section 2 for additional details.)

Setup for Comprehensive Cohort Simulation. Our focus in the comprehensive simulation of cohort labor supply is on individuals born since 1917. The oldest individuals in these cohorts attained age 60 ("retirement age") in 1977, prior to the emergence of employer-sponsored DC pension plans. Individuals in later cohorts were increasingly likely to be offered DC plans by their employers. As shown in Figure 3, out of all workers age 50-59, 24 percent of those born in 1959 had an employer-sponsored DC plan as their main retirement plan at their current job, while 28 percent had a DB plan, and 48 percent had no employer-sponsored plan. This compares to 5 percent DC and 53 percent DB (42 percent no plan) for workers in the same age range born in 1925. A clear trend towards DC accounts and away from DB pensions is apparent. $^{16}$

We use the proportions shown in Figure 3 to weigh the simulated labor force exit profiles for individuals in three different private pension states: (1) DB plan, (2) DC plan, and (3) no plan. For each type of individual we obtain the employment spells and calculate the average labor force participation behavior across types for each cohort using the distribution of pension status ("DB", "DC", "No plan"). Since we do not observe the empirical distribution of pension type during age 50-59 for cohorts born before 1925 and after 1959 in the SIPP data, we impute the

\footnotetext{
${ }^{15}$ Since Social Security pension wealth is indexed to the price level after age 60 since 1972, in the absence of earnings replacements the PIA is constant in real terms after that age. Consequently, the adjustments for early and delayed take-up are real rates.

${ }^{16}$ The reason for using age 50-59 data is that workers who are younger may be more likely to not work a career job. Past age 59, non-participation due to retirement is increasingly likely, which is endogenous to pension type: Since DC pensions offer greater retirement flexibility, we would expect individuals with DC pensions to be more represented during retirement age.
} 
missing values using forward and backward extrapolation of the linear trends of DC type and the proportion without a pension at the current job. ${ }^{17}$

We simulate the model for annual cohorts, realistically specifying key economic variables in the model that vary over time (across cohorts) such as Social Security policy parameters (payroll taxes, taxable earnings limits), the taxation of income, and labor market conditions (wage rate, unemployment rate) as explained in the previous section.

Simulating life time labor supply profiles (age 25 to 94) for more recent cohorts requires that we make assumptions regarding the values of these variables beyond the present. In our main simulation, we assume that the taxation and Social Security policy parameters remain at their 2011 levels. The Unemployment rate is set to 5 percent after 2011, consistent with estimates of the natural rate of unemployment. The interest rate is set to 1.56 percent after 2011 , consistent with the long-run average 1940-2011 (see Table 2).

We report simulated labor force participation rates in five five-year age groups: $45-49, \ldots$, 65-69. This facilitates the comparison to commonly reported labor force statistics (see Figures $1 \mathrm{a}$ and $1 \mathrm{~b})$. To eliminate age structure effects within age groups, we weigh our predictions with the observed annual population shares.

\section{Results}

The values of the parameters estimated from the structural model are shown in Table 3 . The associated Social Security benefit claim age distribution is displayed in Table 4. We compare the DB pension system with the DC pension system and report the different labor force participation rates for age 59-70 in Figures 5 and 6. Further details and discussion on labor supply, consumption and assets are provided in the Technical Appendix A.5.

Table 3 presents the estimates of the parameters in the utility function for males, age 25-94, born in 1917. For the reasons explained above, all individuals are assumed to have a DB pension plan. Since the economic environment changes over time, we set the income tax schedule, Social Security payroll tax rate and maximum taxable amount, and unemployment rate

\footnotetext{
${ }^{17}$ For example, for the 1965 cohort- the youngest cohort needed to calculate the participation rate at ages 45-49 in 2010 - we predict 18.4 percent of workers will have a DB plan as primary plan, 29.9 percent will have a DC plan, and 51.8 percent will have no employer-sponsored plan.
} 
consistent with the real time data, namely an individual born in 1917 may face different tax rates at age 25 and age 60 . The real time unemployment rate is in particular a measure for economic cycle.

The coefficient of relative risk aversion (or the inverse of the intertemporal elasticity) for consumption is 3.393, which is similar to previous estimates from studies that rely on different methodologies. ${ }^{18}$ Identification of this parameter is similar to Rust and Phelan (1997) who estimate a dynamic model of labor supply and Social Security acceptance decisions. Within this framework, the estimated value of the coefficient of relative risk aversion means that individuals are risk averse and would save more in order to buffer themselves against the risk of bad income shocks in the future.

The fixed cost of work, $\theta_{p}$, is estimated to be 273 hours, which generates a reservation number of work-hours. Individuals will either work more than this many hours or will not work at all. The reservation number of work-hours depends on assets, wages, and health status and AIME. At age 62, for example, individuals born in 1917 never choose to work fewer than 726 hours per year. This is similar to French's (2005) estimate of 885 hours and Cogan's (1981) estimate of 1,000 hours per year. The fixed cost level is correlated with Social Security claim at early retirement age 62. Generally speaking, the higher the fixed cost of work, the more likely individuals retire at age 62 and claim Social Security benefits given all else constant.

In addition, the model generates an estimate of hours of leisure lost for poor health, $\phi$, as 311.2. The number is consistent with estimate from French (2005) who find a value between 191-318 hours depending on different specification. Individuals with poor health tend to claim for Social Security benefits earlier, so a higher amount of leisure lost for poor health may cause a larger proportion of eligible population to claim Social Security benefits before the Full Retirement Age of 65.

Table 4 displays the simulated and actual Social Security benefit claiming age distribution for males in the 1917 birth cohort. The most prominent feature of the data is that most males in that cohort exited the labor force in their mid-60's, with pronounced peaks in benefit take-up at ages 62 and 65-precisely the ages of eligibility for early and full Social Security benefits, respectively. Our model can explain the peaks of Social Security benefit take-up at age 62 and 65 in the presence of defined benefit pensions. The peak at 62 may be the result of borrowing

\footnotetext{
${ }^{18}$ See Auerbach and Kotlikoff (1987) and Attanasio and Weber (1995) for reviews.
} 
constraints, since it is illegal to borrow against future Social Security benefits (see Rust and Phelan 1997). The peak at age 65 may be explained by the fact that benefits received after the FRA are less than actuarially fair for most individuals (see Myers and Schobel 1992; Heiland and Yin 2012).

The model overestimates early benefit take-up for men in the 1917 birth cohort. As shown in Table 4, the actual proportion claiming at age 62 is 35.2 percent for men, while the model predicts 55.1 percent. For more recent cohorts, and for female beneficiaries, the rates of take-up at age 62 are higher and more consistent with the predicted values. One potential explanation for the overestimation is that we assume that poor health causes leisure lost in the utility function. It is possible, however, that individuals with inexpensive health insurance have a smaller leisure loss from being in poor health, so they tend to postpone their Social Security benefit claims (Rust and Phelan 1997).

DB versus DC Pensions: Effect on Labor Supply and Social Security Benefit Take-up. In addition to the pension structure with DB plans only, which is characteristic of the 1917 birth cohort, we simulate the model with a DC pension structure whereby the employer replaces a DB plan with a DC plan, offering a 50 percent employer match up to 10 percent of employee's salary. Assuming that the other parameters take on the same values as for the 1917 cohort in the "DB only" environment, we illustrate the effect of DC pension ownership on labor supply and Social Security benefit take-up behavior.

We find that the structure of the private pension system has significant effects on labor supply. The annual hours worked over age 59-70 for DB and DC pension owners are shown in Figure 5. Older individuals with employer-sponsored DB pensions tend to work fewer hours and have a lower labor force participation rate compared to those with employer-sponsored DC pension accounts. On average, between ages 55 to 70, DB pension owners work 282.60 hours less at each age than DC pension owners. The contrast between the two pension environments is particularly stark between ages 60-70; here the difference in hours worked less by DB pension owners is 367.68 hours, on average.

In addition, $\mathrm{DB}$ pension owners also tend to have a lower labor force participation rate compared to DC pension owners. Based on the results for the 1917 cohort, the average labor force participation rate of DB pension owners is 46.6 percent for age 60-70, while the average 
rate for DC pension owners is 61 percent. The labor force participation rates over age 60-70 for DB and DC pension owners are shown in Figure 6.

Looking at the interaction between private and public pensions (Social Security), we find evidence that the type of employer-sponsored pension matters for Social Security benefit take-up behavior. The simulated Social Security benefit claiming age distribution is shown in column 3 in Table 4. Compared with the environment with a DB pension, individuals with a DC pension tend to claim Social Security benefits earlier, resulting in a larger concentration at age $62 .{ }^{19}$ The pattern suggests that some proportion of individuals has not been able to accumulate sufficient tangible net worth to be able to finance significant retirement consumption prior to age 62 .

The difference in labor supply between DB and DC pension owners can be explained as follows. First, the accrual aspects of the DB pensions and tax incentives explain a large part of job exits between ages 55 and 70. The model of DB pension accrual allows for discontinuous jumps in pension accrual at ages 55, 60, 62 and 65. As Gustman and Steinmeier $(1986,1999)$ and Stock and Wise (1990a) point out, discontinuities in pension accrual are potential explanations for the high job exit rates at ages 62 and 65 . When we force pension accrual to be smooth, the downturn in labor force participation rates at the early retirement ages becomes much smaller, which is consistent with the findings in French (2005). Because pension income is taxed and taxation is progressive, there is a jump in an individual's marginal tax rate if she continues to work and begins receiving pensions. Hence, the tax-together with the DB eligibility age_-is also an important labor supply disincentive. Second, as a retirement saving account, DC pensions do not discourage labor supply during older ages. In fact, the employer contribution to the DC pension may implicitly increase the return to labor, resulting in a greater supply of labor.

Cohort Simulation: Labor Force Participation 1977-2010. Equipped with the understanding of the labor supply incentives provided by DB and DC pension ownership, we are now in a position to conduct a comprehensive cohort analysis of labor force participation. As explained above, we solved the model in three exclusive states, "DB", "DC", and "No plan," and

\footnotetext{
${ }^{19}$ This effect would likely be even more pronounced if we accounted for the Social Security Earnings Test. In the absence of this feature, some DC pension holders may be less likely to claim Social Security benefits early as they (incorrectly) perceive the early take-up penalty as irreversible (see Benítez-Silva and Heiland 2007).
} 
then aggregated the results into cohort (age-specific) outcomes using the cohort-specific proportions shown in Figure 3 (adjusted for age structure). ${ }^{20}$

Figure 7 shows the resulting labor force participation rates in age groups 45-49, 50-54, 5559, 60-64, and 65-69 over the time period 1977-2010. The graphs show the expected pattern in the levels, namely, labor force participation is greater among younger age groups. An average, 94.4 percent of individuals age 45-49 participate and 91.9 percent participate among 50-54 year olds. This compares to an observed participation rate of around 89.7 percent for men in the combined age group (see Figure 1a). For the important 60 to 64 year old group, the rate predicted in our simulations over this time period is 62.7 percent. This matches the observed male average participation rate in this age range fairly well. The latter number is 56.9 percent as shown in Figure 1a.

Looking at the predicted trends in labor force participation in Figure 7, we note that participation of the three youngest age groups is very stable over time with evidence of a small, gradual decline since. For example, participation among 45 to 49 year-olds is predicted to be 94.3 percent in 2010, a decline of 0.5 percentage points from 1977. A decline of the same magnitude is found for the age group 50-54. As shown in Figure 1a, we see the same negative trend in male participation rates in this age range, consistent with greater disincentives to work due to higher life time tax burden. ${ }^{21}$ However, it is clear that the predicted decline understates the observed decline for men by several orders of magnitude.

Turning to the two oldest age groups, the model predicts gradual increases over the time period. For the age group 60-64, predicted labor force participation increases from 61 percent in 1987 to 65.6 percent in 2010. It was essentially flat in the ten year period prior to 1987 . The increase for the 65 to 69 year-olds is less pronounced initially but accelerates during the past two decades: the predicted participation rate rises from 43.5 percent in 1992 to 48.1 percent in $2010^{22}$

\footnotetext{
${ }^{20}$ The spikes in the labor force participation rates in 1993 and 2001 reflect period responses by the agents in the model to the sharp reductions in the income tax rates that occurred in these years. In 1993 and 2001, incomes below $\$ 49,600$ (in 2011 dollars) were tax-exempt. Since older individuals are more likely to earn this income level, their labor supply decisions are affected most. The model overstates the response to such tax incentive because individuals in the model can increase their work load freely.

${ }^{21}$ The average marginal income tax rate (including the Social Security payroll tax) for a $\$ 50,000$ income level (in 2011 dollars) is 32.05 percent for cohort 1917 from age 25 to 65 . In comparison, the average marginal tax rate is 36.99 percent for individuals born in 1945 over the same age range.

${ }^{22}$ The delayed increase for the oldest age group is consistent with the gradual rise of DC plans, which increasingly replaced DB plans for successive cohorts.
} 
The observed participation behavior of older male and female individuals displays a similar pattern of a pronounced increase in participation behavior during the past two decades as discussed in the introduction (see Figures 1a and 1b). After an initial decline, the labor force participation rate for males age 60 to 64 increased from 54.4 percent in 1988 to 60 percent in 2010. Participation in the labor market by individuals age 65 and older rose from 15.6 percent in 1993 to 20.8 percent in 2010, after decreasing initially and then being flat.

Among women, the age groups 60-64 and 65 and older also show a marked increase over the past two decades, matching the trend observed for men and consistent with the simulation results. Younger age groups, however, do not display the same flat or negative trend observed among men and explained by our framework. Factors outside the realm of our framework and the present emphasis on the pension environment, such as the narrowing of the gender-wage gap and rising employment opportunities for women as well as social changes, have been cited for the secular rise in female labor supply that overlaps with this time period (e.g., Goldin 2007). ${ }^{23}$

To better understand the potential contribution of the shift in the private pension landscape, namely the rising prevalence of DC plans at the expense of traditional DB plans, we contrast the results in Figure 7 that account for the changes in the pension structure to a counterfactual scenario where there are only DB plans. In this hypothetical case, we assume that the share of DB plans would have followed the combined share of DB and DC in Figure 3 over the 19772010 period. ${ }^{24}$

Figure 8 shows the labor force participation rates for this scenario predicted by the model. While the overall trend pattern is similar to the one found when accounting for DC benefits in Figure 7, there are important differences in magnitude at older ages. Inspection of the graphs shows that the increases in the labor force participation rates for ages 50-64 and 65-69 are substantially smaller when only DB pensions are considered. To illustrate this we can calculate the difference in the rates. Comparing labor force participation in 2010 across regimes, we find that under actual pension conditions 65.6 percent of 60-64 year-olds and 48.1 percent of 65-69 year-olds participated, compared to 61.3 percent and 46.5 percent, respectively, under "DB or No

\footnotetext{
${ }^{23}$ The influx of women in the workplace may have contributed to the emergence of employer-sponsored DC pension plans (as well as been affected by it), as portable pensions are more valuable to individuals with less attachment to specific employers due to family constraints (see Aaronson and Coronado 2005).

${ }^{24}$ This may overstate the share of workers with employer-sponsored pension relative to no plan, since some employers would have likely offered no plan in the absence of an option that allows employees to make taxdeductible contributions.
} 
plan." In other words, the results suggest that in the absence of the structural changes in the private pension market, the rise of DC plans at the expense of DB plans and the decline in employer-sponsored pension coverage, the labor force participation rate of workers 60-64 may have been as much as 4.3 percentage points lower in 2010 (1.6 points for ages 65-69).

The differences across regimes for ages 60-64 and 65-69 are also illustrated graphically in Figure 9, which combines the numbers for each pension regime from Figures 7 ("DB, DC and No plan") and 8 ("DB and No plan"). The corresponding graphs for ages 45-49, 50-54, and 5559 can be found in Figure 10. As discussed above, the participation rates for the older populations (ages 60-64 and 65-69) for the realistic pension structure are consistently above the counterfactual scenario where DC plans are unavailable.

Taking the predicted labor force participation rates by pension structure at face value, we can directly relate the implied increases to the observed ones (Figures 1a and 1b), in an attempt to estimate the potential relative contribution of the changes in the private pension environment on labor force participation. Using 1988 as reference period - consistent with the discussion above - and compare it to 2010, we observe an increase in the labor force participation rate among 60-64 year-old males by 5.4 percentage points. For the same interval and age group, the model predicts a 3 percentage points higher participation under "DB, DC, or No plan" compared to "DB or No plan," suggesting that, perhaps, as much as 56 percent of the increase in male labor force participation in this age group can be attributed to the changing pension environment. For women in the same age range, a group that experienced a dramatic increase in labor force participation from 33.8 percent in 1988 to 50.7 percent in 2010, our estimated contribution of the effect of private pensions to the total increase in participation is 18 percent. As discussed in the next section, the remaining portions of the increases in labor force participation may be explained by changes in factors held constant here such as the full retirement age of Social Security and the Delayed Retirement Credit.

As shown in Figure 3, not only did the mix of pension type change across cohorts the share of workers without pension coverage also increased. The previous results reflect both of these developments. In an attempt to disentangle the effect of the change in the pension plan type mix from the effect of coverage, we can calculate the labor force participation rate holding the share of individuals without an employer-sponsored pension plan constant at the level of the 1925 cohort of 41.8 percent (see Figure 3). The share of individuals with a DC pension out of all 
pension holders is assumed to grow at the same proportion as in the data. As a result, holding the percentage without a plan constant, the percentage of pension holders with a DC pension would have reached 31.7 percent in the 1959 birth cohort (26.5 percent DB pension), compared to 28.5 percent (23.8 percent) in the data (see Figure 3$)$.

In this case, the predicted labor force participation rates at older ages for the period 1977-2010 are slightly greater earlier in the period and smaller for later years than the rates above. This of course reflects the fact that the percentage without pension is fixed at the level of the 1925 cohort such that pension ownership is understated (overstated) for earlier (later) cohorts and individuals with no pension tend to work more (negative wealth effect). As a result, the impact of changes in the mix of pension types is mitigated (exacerbated) before (after) the reference cohort.

Holding the share without a pension at 41.8 percent, the predicted labor force participation rate for 60 to 64 year-olds increases from 61 percent in 1977 to 64.7 percent in 2010 (43.2 vs. 47.8 percent for age group 65-69). This 3.7 percentage point increase compares to a 5.6 percentage point increase when taking the rise in the share of workers without a pension into account. Holding the non-pension share constant and assuming that only DB pensions exist, the predicted participation rate for 2010 is 59.9 percent for the 60-64 age group (46.1 percent for 65-69). This suggests that in the absence of the shift to employer-sponsored tax-deductible DC pension plans, the labor force participation rate of individuals 60-64 would have been as much as 4.9 percentage points lower in 2010 (1.7 points for ages 65-69). This compares to a predicted 4.3 percentage point increase for 60 to 64 year-olds (1.6 points for ages 60-64) based on the actual pension shares (see above), suggesting that the declining share in pension ownership between 1977 and 2010 contributed about 0.6 percentage points to the rise in labor force participation for ages 60 64 (0.1 points for ages 65-69).

In supplementary analysis, we investigate the sensitivity of the results discussed above to the assumption of a constant annual (real) rate of return of 3.04 percent. We also use the model to predict labor force participation of older workers over the next decade. Figure 11 shows the time path of the participation rate for the three oldest age groups, 55-59, 60-64, and 65-69. The solid lines display the simulated labor force participation rates for a real annual rate of return of 3.04 percent (as above) while the dotted lines show the rates when the actual (real) interest rates 
(calculated from Table 2) are used. ${ }^{25}$ The results are very similar for the two interest rate scenarios, reflecting the fact that over the life cycle the volatility in rate of returns largely averages out.

We also see that a continuation of the trend toward greater labor force attachment among the older population over the next decade can be expected. By 2020 the labor force participation rate is predicted to increase by 1 percentage point for 65-69 year-olds, by 1.6 percentage points for the 60-64 year-olds, and by 0.3 percentage points for the 55-59 year-olds, relative to their 2010 levels (for an interest rate of 3.04). These increases primarily reflect the rise in the share of individuals with DC pensions. If we hold the proportion without pension constant at the level of the 1925 cohort (41.8 percent) to isolate the effect of the greater DC share among pensions, as we did above, then the predicted increases in participation are slightly greater, especially for the age group 60-64, for the reasons explained above.

Social Security Reform in a DB and DC Pension Environment. The previous section abstracts from changes in Social Security policy, namely the increases in the Delayed Retirement Credit (DRC) and the Full Retirement Age (FRA) that took place during the 1977-2010 period. (In the simulation all cohorts are subject to a DRC of 3 percent per year and an FRA of age 65.) In this section we illustrate how such policy changes affect labor supply and Social Security benefit take-up behavior, conditional on the type of pension owned.

The first set of policy changes considered are increases in the DRC. Specifically, we look at the effect of a rise in the DRC from 3 to 5.5 percent annually, based on the 1933 birth cohort which faced a DRC of 5.5 percent. Then we analyze the rise in the DRC from 3 to 8 percent, based on the 1943 cohort - which faced a DRC of 8 percent. As discussed above, the actual increase in the DRC occurred fairly gradually between beneficiaries born in 1917-1924 (3 percent annual DRC applies), born in 1933-1934 (5.5 percent), and those born in 1943 and thereafter ( 8 percent). Raising the DRC increases the incentive to take up benefits after FRA and - all else equal — we expect it to shift the claiming age distribution of Social Security benefits towards later ages.

\footnotetext{
${ }^{25}$ Interest rates after 2011 are assumed to be 1.56 percent. All other variable and parameter values are the same across cases and as in the main scenario.
} 
We simulate the effect on behaviors for individuals born in 1933 and 1943, assuming the same preference parameters as above (estimated from the 1917 male cohort) and the cohortspecific values for the economic variables discussed above (see Table 2). To illustrate how the private pension environment mediates the effect of Social Security policy change on individuals' claiming behavior, we simulate the model for individuals with either a DB pension or a DC pension. Table 5 provides a summary of the effect on the distribution of age at Social Security benefit take-up when increasing the DRC from 3 to 5.5 percent for the 1933 cohort (top part of the table) and when increasing it from 3 to 8 percent for the 1943 cohort (bottom part). Since take-up is inversely related to labor supply, these results also speak to the sensitivity of labor force participation at older ages to DRC policy.

The results show the proportion of people who claim Social Security benefits after age 65 increases slightly, suggesting lower labor supply between age 62 and 65 . While the effects are small, perhaps owing to the fact that the vast majority of beneficiaries claim much before the FRA and even at a DRC rate of 8 percent per year benefits after FRA are actuarially unfavorable for many individuals, the DB pension plan owners are marginally more responsive to the greater incentive to claim later compared to the DC plan owners. If we compare the age distributions of Social Security benefit take-up of cohort 1943, about half (53 percent) of DB pension owners who delay take-up claim benefits at age 69, while almost three quarters (72 percent) of DC pension owners who delay take-up claim their Social Security benefits at age 66. A similar pattern applies to the 1933 birth cohort. The pattern is consistent with the idea that individuals with DC pensions are somewhat more dependent on public pension wealth than individuals with a DB pension. $^{26}$

The second policy that we investigate is Social Security retirement age reform. Specifically, we consider the increase in FRA from 65 to 66 that occurred between beneficiaries born in 1937 (and earlier) and those born in 1943-1954. As before we simulate individuals with either DB or DC plans for the 1943 cohort, using the preference parameters estimated previously and the economic conditions of individuals born in 1943.

Figures 12 and 13 present graphs of the Social Security benefit claiming distribution by FRA and type of pension owned. Not surprisingly, the results show that the Social Security benefit

\footnotetext{
${ }^{26}$ This interpretation is consistent with the fact that consumption levels of DC owners are lower at traditional retirement ages compared to DB owners as discussed in the Technical Appendix A.5 and shown in Figure A-3.
} 
take-up age distribution stretches further to the right when the FRA is increased to age 66 from age 65. Consequently, the peak at 65 moves to age 66 as the FRA increases from 65 to 66 . As suggested by the graphs, there are only small differences in how individuals with DB versus DC pensions respond to this policy change. Individuals with a DC pension plan tend to be heavily concentrated at the earliest take-up age (age 62), a phenomenon largely unaffected by the increase in the FRA, resulting in DC holder being marginally less responsive to increases in the FRA than DB holders, consistent with our analysis of changes in the DRC above.

The shift in the claiming age distribution toward later take-up implies greater labor supply at retirement ages. Table 6 displays the annual hours worked by males for cohort 1943, at which the FRA reaches 66. As expected the increase in FRA causes the average annual working hours to increase under either pension type. We observe substantial differences in labor supply by type of pension owned: DB pension owners work about 23 hours more on average from age 62 to 70, while DC pension owners only work about 11 hours more, on average.

\section{Summary and Conclusion}

The rise in the share of workers covered by employer-sponsored defined contribution pension plans over the past three decades constitutes a fundamental change in the American pension landscape. Today, the majority of workers with pension benefits have a defined contribution (DC) plan as their primary occupational retirement plan. The tax-deductibility of contributions, employer-matching, and the flexibility to withdraw resources at older ages permitted by DC plans provides different incentives for labor supply behavior than normal savings accounts and traditional defined benefit (DB) plans that offer a lifetime annuity based on employee tenure and wages.

This paper develops a life cycle model of retirement that incorporates important incentives provided by DB and DC pensions as well as Social Security's old-age retirement program. The model extends previous life cycle retirement frameworks (e.g., French 2005) by incorporating employer-sponsored tax-deferred DC pension plans. It can assist researchers and policy makers in analyzing the complex interrelations of labor supply decisions, retirement behavior, and wealth accumulation. The novel framework can be used to analyze (i) the incentives for labor supply and retirement behavior provided by DB and DC pensions, (ii) the interaction of DB and 
DC pensions with Social Security's Old-Age retirement benefit program, and (iii) the tax incentive for savings behavior and retirement wealth accumulation.

We show that the wealth accrual characteristics in DB plans are closely tied to the timing of the exit from the labor force. In particular, the accrual aspects and the taxation incentives can explain the high concentration of job exits between ages 55 to 65 , consistent with previous evidence (see Friedberg and Webb 2005; Gustman and Steinmeier 1986, 1999; Stock and Wise 1990a). In contrast, DC pensions do not discourage labor supply at older ages and the matching of contributions by employers provides an incentive to increase labor supply over the life cycle.

We estimate the preference parameters of the structural model and use the structural framework to study the effects of the changing pension environment and Social Security retirement policy on labor supply and retirement behavior. Specifically, we conduct a comprehensive cohort-based simulation analysis of labor force participation behavior in the period 1977-2010. The results underline the significance of the introduction and rising popularity of employer-sponsored tax-deductible DC pension at the expense of DB plans in explaining the rise in labor force participation of older Americans. We estimate that in the absence of DC pension plans the labor force participation rate of workers age 60-64 in 2010 would have been as much as 4.9 percentage points lower (1.7 points for ages 65-69), holding the share of individuals without employer-provided pension constant. The recent rise in the Full Retirement Age (FRA) - the age at which individuals can claim full Social Security benefitsalso contributed to the increase in labor force participation, consistent with recent evidence from studies on the trends in labor force participation of older men (Mastrobuoni 2009; Blau and Goodstein 2010).

Looking at the interrelations between private pension and public pensions, we show that the type of employer-sponsored pension matters for Social Security benefit take-up. Individuals with a DC pension tend to claim Social Security benefits earlier than individuals with a DB pension. This suggests that the shift from DB to DC pensions may have contributed to the documented rise in early Social Security benefit take-up across cohorts of beneficiaries born between 1911 and 1937. Statistics from Social Security's Master Beneficiary Microdata (MBM) suggest that the proportion of male beneficiaries who claimed retirement benefits in the 12-months after turning 62 increased from 39.1 percent to 46 percent across the 1911-1937 cohorts (see Figure 4). 
Finally, we show that DC pension holders are more concentrated at the Early Retirement Age (ERA), the earliest take-up age for Social Security old-age retirement benefits (currently age 62), and are less responsive in their claiming and labor supply behavior to FRA increases than DB pension holders. This result is particularly noteworthy for policy makers in light of the designated (gradual) increases in the FRA from currently age 66 to age 67 for beneficiaries born after 1954 that will result in a further 5 percentage point reduction in pension benefits when takeup occurs at ERA. Given that future generations of retirees will be even more dependent on DC pensions than current generations, our findings suggest that their Social Security benefit take-up and labor supply behavior may be less responsive than previous generations to the scheduled increases in the FRA to age 67 and further increases to the (full) retirement age currently debated. 


\section{Technical Appendix}

\section{A.1 Computation of AIME}

Social Security benefits are based on the beneficiary's 35 highest earnings years. The average monthly earnings over the 35 highest earnings years are called Average Indexed Monthly Earnings, or AIME. We annualize AIME and compute it using the following formula for individuals 30-59:

$$
A I M E_{t+1}=A I M E_{t}+\left(W_{t} H_{t}\right) / 35
$$

We assume the individual enters the labor force at age 25. Since AIME is computed using the 35 highest earnings years, AIME increases unambiguously if the individual works and is younger than 60 . If age is 60 and greater, AIME can still increase, but only if the new earnings are greater than earnings in the previous year of work. The high earnings year will replace a low earnings year when computing Social Security benefits. ${ }^{27}$ Therefore, the formula for individuals 60 and older becomes:

$$
A I M E_{t+1}=A I M E_{t}+\max \left\{0, \frac{W_{t} H_{t}-A I M E_{t}}{35}\right\} .
$$

Lastly, we account for the fact that AIME is capped. In 1987, the maximum AIME level was $\$ 43,800$ in 1987 dollars. AIME is converted into a Primary Insurance Amount (PIA) using the following formula:

$$
P I A_{t}=\left\{\begin{array}{c}
.9 \times A I M E_{t} \quad \text { if } A I M E_{t}<\$ 3,720 \\
\$ 3,348+.32 \times A I M E_{t} \quad \text { if } \$ 3,720 \leq A I M E_{t}<\$ 22,392 \\
\$ 9,695+.15 \times A I M E_{t} \quad \text { if } A I M E_{t} \geq \$ 22,392 .
\end{array}\right.
$$

Social Security benefits $s s_{t}$ depend on both, the Primary Insurance Amount (PIA) and the age at which the individual first receives Social Security benefits. The pre-earnings test benefits for a Social Security beneficiary will be equal to PIA if the individual first receives benefits at age 65. For every year before age 65 the individual first draws benefits are reduced by 6.67 percent and for every year that benefit receipt is delayed past FRA until age 70 benefits increase by 3 percent according to the rules of the actuarial adjustment of benefit take-up and the Delayed Retirement Credit (see Myers 1993).

\footnotetext{
${ }^{27}$ Considering the size of the model, we assume that the high earnings year replaces an average earnings year, the same as the modeling in French (2005).
} 


\section{A.2 Defined Benefit Pensions}

There are two important aspects of DB pensions that we consider. First, pension wealth is illiquid until the early retirement age. Second, pension accrual rates are higher for individuals in their $50 \mathrm{~s}$ than at other ages.

We begin with the liquidity aspect. Because both Social Security benefits and pensions are annuities, we load DB pension wealth onto PIA. If the individual is age-eligible for DB pension benefits, then pension benefits are:

$$
D B_{t}^{*}=\delta_{0}\left(\delta_{1}+\delta_{2} P I A_{t}+\delta_{3} \max \left\{0, P I A_{t}-5000\right\}\right)
$$

where the values for the parameters $\delta_{0}, \delta_{1}, \delta_{2}, \delta_{3}$ are taken from Gustman and Steinmeier (1999). A spline function is used to estimate $\delta_{1}, \delta_{2}, \delta_{3}$. Gustman and Steinmeier (1999) show that the ratio of pension wealth to Social Security wealth rises rapidly with PIA. Lastly, we set the scale parameter $\delta_{0}$ so that average pension wealth, described in equation (A-6) below, is $\$ 143,407$ in 2011 dollars (equivalent to $\$ 78,108$ in 1987 dollars) at age 60, which matches estimates for male household heads in Gustman and Steinmeier (1999).

We treat the decline in Social Security benefits for early take-up of old-age benefits as equivalent to a decline in PIA. Since in our implementation changes in PIA (a state variable) affect DB pension benefits, we have to correct the DB benefits when early take-up occurs. This is accomplished by adjusting PIA using the method described in French (2003), resulting in DB pension benefit being unaffected by Social Security benefit claiming decisions.

Next, consider the fact that pension accrual rate is greater for individuals in their 50s than those at other ages. However, the pension accrual benefit formula in equation (A-4) does not imply that pension accrual, pacc $_{t}^{*}$, for individuals in their $50 \mathrm{~s}$ is much higher. ${ }^{28}$ To overcome this problem, we take a second pension accrual measure based on age and labor income $\operatorname{pacc}_{t}=\operatorname{pacc}\left(W_{t} H_{t}, t\right)$ :

$$
\operatorname{pacc}_{t}=\mu_{0} \times\left(\mu_{1}+\mu_{2} W_{t} H_{t}+\mu_{3} \max \left(0, W_{t} H_{t}-15,300\right)\right) \times \mu_{4}(t) \times W_{t} H_{t} .
$$

The parameters in equation (A-5) are estimated by the method described in French (2003). The DB benefit in equation (7) is then expressed as follows:

\footnotetext{
${ }^{28}$ The pension accrual is $1 / 2$ as the increase in the present value in future benefits caused by a rise in future benefits. Let pacc $_{t}$ denote the pension accrual in period t, then $\operatorname{pacc}_{t}^{*}=\Gamma_{t}\left(D B_{t}^{*}-D B_{t-1}^{*}\right)$, where $\Gamma_{t} \equiv \frac{1}{1+r} \sum_{k=t}^{T} \frac{F_{k}-F_{t}}{(1+r)^{k-t}} I\{k \geq 62\}$.
} 


$$
D B_{t}=D B_{t}^{*}+\left(p a c c_{t}-p a c c_{t}^{*}\right) .
$$

The term $\left(\right.$ pacc $_{t}-$ pacc $\left._{t}^{*}\right)$ is positive in older ages, and negative in younger ages.

\section{A.3 Numerical Algorithm}

The problem is solved numerically, backwards from the last period of life. At each date, one can solve for the decision rules based on the following Bellman equation:

$$
\begin{gathered}
V_{t}\left(X_{t}\right)= \\
\max _{\left\{C_{t}, H_{t}, S_{t}, B_{t}\right\}}\left\{U\left(C_{\mathrm{t}}, \mathrm{H}_{\mathrm{t}}, \mathrm{M}_{\mathrm{t}}\right)+\mathrm{e}^{-\vartheta_{\mathrm{t}+1} \beta \times}\right. \\
\left.\sum_{\mathrm{M} \in\{\text { good,bad }\}} \int \mathrm{V}_{\mathrm{t}+1}\left(\mathrm{X}_{\mathrm{t}+1}\right) \mathrm{dF}\left(\mathrm{W}_{\mathrm{t}+1} \mid \mathrm{W}_{\mathrm{t}}, \mathrm{M}_{\mathrm{t}+1}, \mathrm{t}\right) \operatorname{prob}\left(\mathrm{M}_{\mathrm{t}+1} \mid \mathrm{M}_{\mathrm{t}}, \mathrm{t}\right)+\left(1-\mathrm{e}^{-\vartheta_{\mathrm{t}+1}}\right) \beta \mathrm{b}\left(\mathrm{A}_{\mathrm{t}+1}\right)\right\}
\end{gathered}
$$

The above equation indicates that each head of household faces two types of uncertainties, one of which is the health uncertainty, and the other is risk to labor earnings (income shock). Gauss-Hermite quadrature is performed to evaluate the expectation in Expression (A-7).

To solve for the optimal solutions, the endogenous state variables $X_{t}=\left(A_{t}, W_{t}, D C_{t}, B_{t}, M_{t}, A_{M} E_{t}\right)$ are discretized into a grid of $(50 \times 15 \times 20 \times 2 \times 2 \times 5)$ over the following ranges: non-pension wealth $A_{t} \in(0,50,000,000)$, hourly wage $W_{t} \in(0,50)$, pension wealth $D C_{t} \in(0,10,000,000)$, Social Security benefit claim status $B_{t} \in\{0,1\}$, health status $M_{t} \in\{0,1\}$, and average wage $\operatorname{AIME}_{t} \in(0,100,000)$.

In order to capture the curvature of the policy rules at low values of non-pension and pension wealth, the grid will be finer for $A_{t} \in(0,50,000)$ and $\mathrm{DC}_{t} \in(0,30,000)$. At each point in the state space, in order to find the optimal choices, we need further discretize the choice space $\left\{\mathrm{C}_{t}, \mathrm{H}_{t}, \mathrm{~S}_{\mathrm{t}}, \mathrm{B}_{\mathrm{t}}\right\}$. The consumption level, $C_{t}$, is discretized into 50 grids over $(0,5,000,000)$ and hours of work, $H_{t}$, is discretized into 10 grids over $(0,3,500)$. The pension savings amount, $\mathrm{S}_{\mathrm{t}}$, is discretized into 30 grids over $(-10,000,000,30,000)$, where the upper bound is 20 percent of the maximum labor income (i.e. the contribution limit in the pension account), and the lower bound is the negative value of the maximum of the pension account wealth. When $S_{t}<0$, the head of household will withdraw money out of the defined contribution account, and make contributions otherwise.

For each value in the state space $\left\{A_{t}, W_{t}, D C_{t}, B_{t}, M_{t}, A_{M} E_{t}\right\}$, we find the value in the consistent choice space $\left\{\mathrm{C}_{\mathrm{t}}, \mathrm{H}_{\mathrm{t}}, \mathrm{S}_{\mathrm{t}}, \mathrm{B}_{\mathrm{t}}\right\}$ that maximize the value function. A four-dimensional linear interpolation is used to calculate the value function for points in the state space that lie between the grid points, and extrapolation is applied when state values move out of the grid. Since extrapolation is much less precise 
than interpolation, we adopted a simple checking approach to assure that the state values in the simulations remains within the grid with probability 0.95 .

In choosing the size and coarseness of the grid, one faces the usual trade-off between precision and computing time. Adding points on the grid gives a finer approximation of the policy rules, but also increases the need to calculate equation (A-7). The current size of this problem takes 6.2 hours on a 64bit Xeon processors server. ${ }^{29}$ After paralleling the program onto 64 processors using Message Passing Interface (MPI), the solution can be obtained in about 350 seconds. As the number of processors increases, the marginal time that can be saved may be compensated by the time spent in message passing (see Swann 2000 for details). The number of processors chosen here is at the point where marginal time gains equal to marginal time losses.

\section{A.4 Method of Simulated Moments}

Suppose there are $J$ moments in the estimation. Since each element of those moments is the expectation of one distribution, we define $\zeta^{j}$ as the variable for each distribution, $j=1, \ldots, \mathrm{J}$, and $I_{j}$ the corresponding number of observations of that variable. The simulated expectation for variable $j$ and parameter set $\theta$ is $\bar{\zeta}^{j}(\theta)$. Let $g(\theta)=\left[g_{1}(\theta), \ldots, g_{J}(\theta)\right]$ be a vector in which $g_{j}(\theta)=\frac{1}{I_{j}} \sum_{i=1}^{I_{j}} \zeta_{i}^{j}-$ $\bar{\zeta}^{j}(\theta)$, that is, the distance between the actual and predicted moments. The method of simulated moments minimizes the weighted average distance between the actual and predicted distributions $g(\theta)^{\prime} W g(\theta)$, in which $W$ is a weighting matrix.

In the first stage, the identity weighting matrix is used to minimize,

$$
g(\theta)^{\prime} \operatorname{Ig}(\theta)
$$

with respect to $\theta$. Using the computed $\hat{\zeta}$, an estimate variance-covariance matrix $\widehat{\Omega}$ can be constructed,

$$
\widehat{\Omega}=E\left[(\zeta-\bar{\zeta}(\theta))(\zeta-\bar{\zeta}(\theta))^{\prime}\right]
$$

with $\widehat{\Omega_{j}}=\frac{1}{I_{j}} \sum_{i=1}^{I_{j}}\left(\zeta_{i}^{j}-\hat{\zeta}^{j}(\theta)\right)^{2}$ on the diagonal, and zeros off-diagonal.

$$
W=\widehat{\Omega}^{-1} \text { is the optimal weighting matrix, so in the second stage }
$$

\footnotetext{
${ }^{29}$ We are using the facilities of the CUNY High Performance Computing Center (CHPCC), a 4,500sqf. facility on Staten Island, NY, equipped with multiple clusters and a 1,280 CPU Cray XE6 supercomputer (www.csi.cuny.edu/cunyhpc/).
} 


$$
S(\theta)=g(\theta)^{\prime} \widehat{\Omega}^{-1} g(\theta)
$$

is minimized. The distribution of the resulting estimate $\tilde{\theta}$ is

$$
\sqrt{I}\left(\tilde{\theta}-\theta_{0}\right) \stackrel{d}{\rightarrow} N(0, Q)
$$

where I is the number of observations, and letting $\varsigma$ be the ratio of the number of observations to the number of simulated points,

$$
Q=(1+\varsigma)\left(G_{\theta} \widehat{\Omega}^{-1} G_{\theta}\right)^{-1}
$$

where $G_{\theta}=E\left[\partial g(\tilde{\theta}) / \partial \theta^{\prime}\right]$.

To test the overidentifying restrictions, we use

$$
\chi_{J-5}^{2}=\operatorname{Ig}(\tilde{\theta})^{\prime} \widehat{\Omega}^{-1} g(\tilde{\theta})
$$

which is distributed asymptotically as Chi-squared with $J-5$ degrees of freedom.

\section{A.5 Predicted Profiles of Wage, Consumption and Assets}

In this section, we describe the simulated life cycle profiles of annual hours worked, hourly wage, consumption, and assets based on the calibrated parameters in Section 3.2, economic and demographic values in Section 4.1 and estimates in Section 5.1. Our discussion will focus on cohort 1917, which is the cohort in our estimation. We compare two cases, one of which is for Defined Benefit (DB) pension owners, and the other is for Defined Contribution (DC) pension owners. Accompanying figures can be found in a Figures Appendix.

Figure A-1 displays the predicted annual hours worked for DB pension owners and DC pension owners from age 25 to 65 , the main working period. Since DC pension provides employees an opportunity to save in an individual retirement account, and the employer matching policy implicitly increases the return to labor supply, DC pension owners tend to work more hours than DB pension owners, by about 356 hours on average.

The wage equation, Equation (4) in Section 2.1, is a function of hours worked, age, health status, and labor income uncertainty. Therefore the labor supply decision affects the actual wage earned. The simulated hourly wage from age 24 to 65 is shown in Figure A-2 for DB pension and DC pension owners respectively. Both wage profiles are hump-shaped, and peaked around age 50-55, which is consistent with previous studies of labor income, such as Gourinchas and Parker (2002) and French (2005). Since 
DC pension owners work more than DB pension owners on average, the hourly wage is higher for DC pension owners.

The simulated consumption profiles are displayed in Figure A-3. The consumption profiles are also hump shaped and tend to track work-hours over the life cycle. This profile can be compared to the life cycle consumption profiles of French (2005). In his study, consumption grows 44 percent between ages 30 and 55, and then declines 22 percent between ages 55 and 65 . Our profile shows consumption rising 42 percent and then declining 30 percent in the respective age ranges. The profile peaks at a later age than profiles estimated using Consumer Expenditure Survey data by Gourinchas and Parker (2002).

However, their study may understate consumption of older individuals because they omit data on medical expenses and housing, which tend to be consumed in greater quantities later in life. There are no large differences in consumption between DB and DC pension holders until age 60, after which DB pension benefits become liquid thus significantly boosting the consumption levels of DB pension owners compared to DC holders.

Figure A-4 shows the average asset accumulation by pension plan from age 25 to 65 . The asset value reported is the summation of non-pension wealth and after-tax pension wealth (DC plan). The wealth accumulated by DB pension owners is quite moderate, and the difference between the wealth of DB and DC pension owners are the pretax savings of the DC pension owners and the matching contributions from the employer. After retirement, DC pension owners will liquidate the pension wealth, while DB pension owners will receive annuitized pension benefits from their employer.

Looking at wealth during retirement, DB pension owners receive pension benefits and Social Security benefits annually, and can spend accumulated non-pension wealth. ${ }^{30}$ DC pension owners receive Social Security benefits annually, liquidate their DC pension wealth and can spend accumulated nonpension wealth. Since DC pension owners work more before retirement, they receive more benefits from Social Security. However, since the model predicts a relative moderate pretax savings level in the DC account (generally less than 10 percent), the retirement wealth for DC pension owners is about 70 percent of the amount of DB pension owners. A similar relationship is found in Health and Retirement Study (HRS) data (e.g. Friedberg and Webb 2005). In the 1992 wave of the HRS, the 25th percentile pension wealth at age 65 of DC pension owners is about 54.6 percent of the wealth of DB pension owners. This percentage is about 50.2 percent at the median and 60.1 percent at 75 th percentile. ${ }^{31}$

\footnotetext{
${ }^{30}$ DB pension owners can save for IRA, which may result in a small amount pension wealth.

${ }^{31}$ HRS (1992 wave) data show that, among individuals age 65 , the pension wealth is $\$ 89,920$ for those with a DB pension and $\$ 49,109$ for those with a DC pension at the 25 th percentile, $\$ 203,949$ for DB pension owners and $\$ 102,298$ for DC pension owners at the median, and $\$ 384,378$ for DB owners and $\$ 230,946$ for DC owners at the 75 th percentile.
} 


\section{References}

Aaronson, Daniel, and Eric French. 2009. The Effects of Progressive Taxation on Labor Supply when Hours and Wages are Jointly Determined. Journal of Human Resources, 44(2): 386-408.

Aaronson, Stephanie, and Julia Coronado. 2005. Are Firms or Workers behind the Shift away from DB Pension Plans? Federal Reserve Board Finance and Economics Discussion Series Working Paper 2005-17. Washington, DC: Federal Reserve Board of Governors.

Attanasio, Orazio P. and Guglielmo Weber. 1995. Is Consumption Growth Consistent with Intertemporal Optimization? Evidence from the Consumer Expenditure Survey. Journal of Political Economy, 103(6): 1121-1157.

Auerbach, Alan J. and Laurence J. Kotlikoff. 1987. Dynamic Fiscal Policy. Cambridge: Cambridge University Press.

Benítez-Silva, Hugo, and Frank Heiland. 2007. The Social Security Earnings Test and Work Incentives. Journal of Policy Analysis and Management, 26(3): 527-555.

Benítez-Silva, Hugo, and Frank Heiland. 2008. Early Claiming of Social Security Benefits and Labor Supply Behavior of Older Americans. Applied Economics, 40(23): 2969-2985.

Blau, David, and Ryan Goodstein. 2010. Can Social Security Explain Trends in Labor Force Participation of Older Men in the United States?, Journal of Human Resources 45(2): 328-363.

Cagett, Macro. 2003. Wealth Accumulation over the Life Cycle and Precautionary Savings. Journal of Business and Economic Statistics, 21(3): 339-353.

Cogan, John F.. 1981. Fixed Costs and Labor Supply. Econometrica, 49(4): 945-963.

Coile, Courtney, and Jonathan Gruber. 2000. Social Security and Retirement. Working Paper 7830. Cambridge, Mass: National Bureau of Economic Research.

Duffie, Darrell, and Kenneth J. Singleton. 1993. Simulated Moments Estimation of Markov Models of Asset Prices. Econometrica, 61(4): 929-952.

French, Eric. 2005. The Effects of Health, Wealth, and Wages on Labor Supply and Retirement Behavior. The Review of Economic Studies, 72 (2): 395-427.

French, Eric. 2003. The Effects of Health, Wealth, and Wages on Labor Supply and Retirement Behavior. The Federal Reserve Bank of Chicago Working Papers 2000-02.

Friedberg, Leora, and Anthony Webb. 2005. Retirement and the Evolution of Pension Structure. The Journal of Human Resources. 40(2): 281-307.

Friedberg, Leora, and Michael Owyang. 2005. Explaining the Evolution of Pension Structure and Job Tenure. The Federal Reserve Bank of St. Louis Working Paper 2002-022D.

Goldin, Claudia. 1994. Labor Markets in the Twentieth Century. Historical Working Paper 58. Cambridge, Mass: National Bureau of Economic Research. 
Goldin, Claudia. 2007. The Quiet Revolution that Transformed Women's Employment, Education, and Family. Working Paper 11953. Cambridge, Mass: National Bureau of Economic Research.

Gourinchas, Pierre-Olivier, and Jonathan A. Parker. 2002. Consumption Over the Life Cycle. Econometrica, 70(1):47-89.

Gruber, Jonathan, and David Wise. 2005. Social Security Programs and Retirement around the World: Fiscal Implications; Introduction and Summary. Working Paper 11290. Cambridge, Mass: National Bureau of Economic Research.

Gustman, Alan, and Thomas Steinmeier. 1986. A Structural Retirement Model. Econometrica, 54(3): $555-584$

Gustman, Alan, and Thomas Steinmeier. 1992. The Stampede Toward DC Pension Plans: Fact or Fiction? Industrial Relations, 31(2): 361-369.

Gustman, Alan, and Thomas Steinmeier. 1999. Effects of Pensions on Savings: Analysis with Data from the Health and Retirement Study. Carnegie-Rochester Conference Series on Public Policy: 271-324.

Heiland, Frank, and Na Yin. 2012. Have We Finally Achieved Actuarial Fairness of Social Security Retirement Benefits and Will It Last? Working Paper.

Ippolito, Richard A. 1997. Pension Plans and Employee Performance. Chicago: University of Chicago Press.

Ippolito, Richard A., and John W. Thompson. 2000. The Survival Rate of Defined-Benefit Plans 19871995. Industrial Relations 39(2): 228-245.

Kotlikoff, Laurence, and David A. Wise. 1989. Employee Retirement and a Firm's Pension Plan. In The Economics of Aging, edited by David A. Wise, 279-330. University of Chicago Press.

Li, Zhe. 2010. Retirement Savings and Portfolio Choices in Taxable and Tax-Deferred Accounts. Working Paper.

Mastrobuoni, Giovanni. 2009. "Labor Supply Effects of the Recent Social Security Benefit Cuts: Empirical Estimates Using Cohort Discontinuities,” Journal of Public Economics, 93: 1224-1233.

Munnell, Alicia H., Kevin E. Cahill, and Natalia A. Jivan. 2003. How Has the Shift to 401(k)s Affected the Retirement Age? Issue in Brief 13. Chestnut Hill, Mass.: Center for Retirement Research, Boston College.

Munnell, Alicia H., and Annika Sundén. 2004. Coming Up Short: The Challenge of 401(k) Plans. The Brookings Institution Press.

Munnell, Alicia H., Francesca Golub-Sass, Mauricio Soto, and Francis Vitagliano. 2006. Why are Healthy Employers Freezing their Pensions? Issue in Brief No. 44. Chestnut Hill, MA: Center for Retirement Research at Boston College (March).

Myers, Rober J. 1993. Social Security. Fourth Edition. Pension Research Council and University of Pennsylvania Press. 
Myers, Robert J., and Bruce D. Schobel. 1990. Early-Retirement Reduction and Delayed-Retirement Increase Factors under U.S. Social Security Law. Transactions, XLII: 295-320.

Lumsdaine, Robin, James Stock, and David A. Wise. 1992. Three Models of Retirement: Computational Complexity versus Predictive Validity. In Topics in the Economics of Aging, edited by David A. Wise, 19-60. University of Chicago Press.

Pakes, Ariel, and David Pollard. 1989. Simulation and the Asymptotics of Optimization Estimators. Econometrica, 57(5): 1027-1057.

Poterba, James, Joshua Rauh, Steven Venti, and David A. Wise. 2006. Defined Contribution Plans, Defined Benefit Plans, and the Accumulation of Retirement Wealth. Working Paper 12597. Cambridge, Mass: National Bureau of Economic Research.

Poterba, James, Steven Venti, and David A. Wise. 2007. The Changing Landscape of Pensions in the United States. Working Paper 13381. Cambridge, Mass: National Bureau of Economic Research.

Rajnes, David. 2002. An Evolving Pension System: Trends in Defined Benefit and Defined Contribution Plans. EBRI Issue Brief No. 249. Washington, DC: Employee Benefit Research Institute (September).

Rust, John, and Christopher Phelan. 1997. How Social Security and Medicare Affect Retirement Behavior in a World of Incomplete Markets, Econometrica, 65: 781-831.

Schirle, Tammy. 2008. Why Have the Labour Force Participation Rates of Older Men Increased Since the Mid-1990s?, Journal of Labor Economics 26(4): 549-594.

Samwick, Andrew. 1998. New Evidence on Pensions, Social Security, and the Timing of Retirement. Journal of Public Economics, 70: 207-236.

SSA-S (various years). Annual Statistical Supplement to the Social Security Bulletin. http://www.ssa.gov/policy/docs/statcomps/supplement/

Stock, James H., and David A. Wise. 1990a. Pensions, the Option Value of Work, and Retirement. Econometrica, 58(5): 1151-1180.

Stock, James H., and David A. Wise. 1990b. The Pension Inducement to Retire: An Option Value Analysis. In Issues in the Economics of Aging, edited by David A. Wise, 205-230. University of Chicago Press.

Swann, Christopher A. 2000. Maximum Likelihood Estimation using Parallel Computing: An Introduction to MPI. Working Paper.

Swann, Christopher A. 2001. Software for parallel computing: the LAM Implementation of MPI, Journal of Applied Econometrics, 16: 185-194. 
Table 1. Calibrated Parameters

\begin{tabular}{|l|l|l|}
\hline Parameter & Descriptions & Value \\
\hline Utility Function & & \\
\hline$\beta$ & Time discount factor & 0.96 \\
\hline$\theta_{B}$ & Bequest weight & 0.1 \\
\hline$K$ & Curvature of bequest function & 500,000 \\
\hline Wage function & & \\
\hline$\alpha$ & Part-time penalty & 0.415 \\
\hline$\rho$ & Autoregressive coefficient of wages & 0.977 \\
\hline$\sigma_{\eta}^{2}$ & Variance of the innovation in wages & 0.0141 \\
\hline Wealth Accumulation & & \\
\hline $\mathrm{r}$ & Interest rate & 0.0304 \\
\hline$\tau$ & Tax structure & (progressive) \\
\hline $\mathrm{DC}$ pension & & $20 \%$ \\
\hline $\mathrm{q}$ & Savings limit of salary & $50 \%$ \\
\hline $\mathrm{m}$ & Employer matching rate if any & $10 \%$ \\
\hline Limit & Employer matching limit of salary & $10 \%$ \\
\hline pnl & Early withdrawal penalty & \\
\hline
\end{tabular}


Table 2. Period Values for Cohort Simulation

\begin{tabular}{|c|c|c|c|c|c|c|}
\hline Year & $\begin{array}{l}\text { Social Security } \\
\text { Payroll Tax } \\
\text { (in \%) }\end{array}$ & $\begin{array}{l}\text { SS Max. Tax. } \\
\text { Earnings } \\
\text { (in current \$) }\end{array}$ & $\begin{array}{l}\text { Hourly Wage } \\
\text { (Manu-facturing, in } \\
\text { \$2010) }\end{array}$ & $\begin{array}{l}\text { Unemployment } \\
\text { Rate (in \%) }\end{array}$ & $\begin{array}{l}\text { Inflation Rate } \\
\text { (CPI-AUC NS, } \\
\text { in \%) } \\
\end{array}$ & $\begin{array}{l}\text { Nominal } \\
\text { Interest Rate (10yr } \\
\text { Treasuries, in \%) }\end{array}$ \\
\hline 1940 & 1.000 & 3,000 & 8.19 & 14.60 & 1.44 & 2.10 \\
\hline 1941 & 1.000 & 3,000 & 9.04 & 9.90 & 11.35 & 2.16 \\
\hline 1942 & 1.000 & 3,000 & 9.76 & 4.70 & 7.64 & 2.46 \\
\hline 1943 & 1.000 & 3,000 & 10.59 & 1.90 & 2.96 & 2.47 \\
\hline 1944 & 1.000 & 3,000 & 11.27 & 1.20 & 2.30 & 2.43 \\
\hline 1945 & 1.000 & 3,000 & 11.08 & 1.90 & 2.25 & 2.30 \\
\hline 1946 & 1.000 & 3,000 & 11.07 & 3.90 & 18.13 & 2.22 \\
\hline 1947 & 1.000 & 3,000 & 10.90 & 3.90 & 10.23 & 2.33 \\
\hline 1948 & 1.000 & 3,000 & 10.76 & 3.75 & 1.27 & 2.39 \\
\hline 1949 & 1.000 & 3,000 & 11.49 & 6.05 & -2.08 & 2.31 \\
\hline 1950 & 1.500 & 3,000 & 12.00 & 5.21 & 8.09 & 2.42 \\
\hline 1951 & 1.500 & 3,600 & 12.20 & 3.28 & 4.33 & 2.62 \\
\hline 1952 & 1.500 & 3,600 & 12.42 & 3.03 & 0.38 & 2.74 \\
\hline 1953 & 1.500 & 3,600 & 13.26 & 2.93 & 1.13 & 3.11 \\
\hline 1954 & 2.000 & 3,600 & 13.45 & 5.59 & -0.74 & 2.38 \\
\hline 1955 & 2.000 & 4,200 & 14.12 & 4.37 & 0.37 & 2.78 \\
\hline 1956 & 2.000 & 4,200 & 14.66 & 4.13 & 2.99 & 3.00 \\
\hline 1957 & 2.250 & 4,200 & 14.97 & 4.30 & 3.62 & 3.80 \\
\hline 1958 & 2.250 & 4,200 & 14.93 & 6.84 & 1.40 & 2.97 \\
\hline 1959 & 2.500 & 4,800 & 15.65 & 5.45 & 1.03 & 4.34 \\
\hline 1960 & 3.000 & 4,800 & 15.76 & 5.54 & 1.71 & 4.15 \\
\hline 1961 & 3.000 & 4,800 & 16.09 & 6.69 & 0.67 & 3.88 \\
\hline 1962 & 3.125 & 4,800 & 16.38 & 5.57 & 1.33 & 3.91 \\
\hline 1963 & 3.625 & 4,800 & 16.67 & 5.64 & 1.64 & 3.99 \\
\hline 1964 & 3.625 & 4,800 & 16.95 & 5.16 & 0.97 & 4.17 \\
\hline 1965 & 3.625 & 4,800 & 17.18 & 4.51 & 1.92 & 4.21 \\
\hline 1966 & 3.850 & 6,600 & 17.36 & 3.79 & 3.46 & 4.81 \\
\hline 1967 & 3.900 & 6,600 & 17.67 & 3.84 & 3.65 & 5.02 \\
\hline 1968 & 3.800 & 7,800 & 18.09 & 3.56 & 4.40 & 5.72 \\
\hline 1969 & 4.200 & 7,800 & 18.16 & 3.49 & 6.18 & 6.57 \\
\hline 1970 & 4.200 & 7,800 & 18.15 & 4.98 & 5.29 & 7.84 \\
\hline 1971 & 4.600 & 7,800 & 18.52 & 5.95 & 3.27 & 6.52 \\
\hline 1972 & 4.850 & 9,000 & 19.24 & 5.60 & 3.65 & 6.11 \\
\hline 1973 & 4.850 & 10,800 & 19.48 & 4.86 & 9.39 & 6.90 \\
\hline 1974 & 4.950 & 13,200 & 19.08 & 5.64 & 11.80 & 7.54 \\
\hline 1975 & 4.950 & 14,100 & 18.99 & 8.48 & 6.72 & 7.86 \\
\hline 1976 & 4.950 & 15,300 & 19.42 & 7.70 & 5.22 & 7.86 \\
\hline 1977 & 4.950 & 16,500 & 19.86 & 7.05 & 6.84 & 7.28 \\
\hline
\end{tabular}

(continues) 
Table 2. (continues)

\begin{tabular}{|c|c|c|c|c|c|c|}
\hline Year & $\begin{array}{l}\text { Social Security } \\
\text { Payroll Tax (in } \\
\text { \%) } \\
\end{array}$ & $\begin{array}{l}\text { SS Max. Tax. } \\
\text { Earnings (in } \\
\text { current \$) } \\
\end{array}$ & $\begin{array}{l}\begin{array}{l}\text { Hourly Wage } \\
\text { (Manufacturing, in }\end{array} \\
\$ 2010 \text { ) }\end{array}$ & $\begin{array}{l}\text { Unemployment } \\
\text { Rate (in \%) }\end{array}$ & $\begin{array}{l}\text { Inflation Rate } \\
\text { (CPI-AUC NS, } \\
\text { in \%) } \\
\end{array}$ & $\begin{array}{l}\text { Nominal Interest } \\
\text { Rate (10yr } \\
\text { Treasuries, in \%) }\end{array}$ \\
\hline 1978 & 5.050 & 17,700 & 20.02 & 6.07 & 9.28 & 8.46 \\
\hline 1979 & 5.080 & 22,900 & 19.72 & 5.85 & 13.91 & 8.91 \\
\hline 1980 & 5.080 & 25,900 & 18.66 & 7.18 & 11.83 & 9.78 \\
\hline 1981 & 5.350 & 29,700 & 18.89 & 7.62 & 8.39 & 13.47 \\
\hline 1982 & 5.400 & 32,400 & 18.79 & 9.71 & 3.71 & 14.30 \\
\hline 1983 & 5.400 & 35,700 & 18.97 & 9.60 & 4.19 & 10.85 \\
\hline 1984 & 5.700 & 37,800 & 18.96 & 7.51 & 3.53 & 13.56 \\
\hline 1985 & 5.700 & 39,600 & 19.00 & 7.19 & 3.89 & 10.16 \\
\hline 1986 & 5.700 & 42,000 & 19.05 & 7.00 & 1.46 & 7.80 \\
\hline 1987 & 5.700 & 43,800 & 18.69 & 6.18 & 4.05 & 8.40 \\
\hline 1988 & 6.060 & 45,000 & 18.53 & 5.49 & 4.67 & 8.92 \\
\hline 1989 & 6.060 & 48,000 & 18.13 & 5.26 & 5.20 & 8.28 \\
\hline 1990 & 6.200 & 51,300 & 18.11 & 5.62 & 5.65 & 8.48 \\
\hline 1991 & 6.200 & 53,400 & 17.84 & 6.85 & 2.60 & 8.28 \\
\hline 1992 & 6.200 & 55,500 & 17.74 & 7.49 & 3.26 & 7.26 \\
\hline 1993 & 6.200 & 57,600 & 17.60 & 6.91 & 2.52 & 5.96 \\
\hline 1994 & 6.200 & 60,600 & 17.67 & 6.10 & 2.80 & 7.10 \\
\hline 1995 & 6.200 & 61,200 & 17.57 & 5.59 & 2.73 & 6.17 \\
\hline 1996 & 6.200 & 62,700 & 17.71 & 5.41 & 3.04 & 6.91 \\
\hline 1997 & 6.200 & 65,400 & 17.74 & 4.94 & 1.57 & 6.49 \\
\hline 1998 & 6.200 & 68,400 & 17.91 & 4.50 & 1.67 & 5.50 \\
\hline 1999 & 6.200 & 72,600 & 18.14 & 4.22 & 2.74 & 5.90 \\
\hline 2000 & 6.200 & 76,200 & 18.04 & 3.97 & 3.73 & 6.10 \\
\hline 2001 & 6.200 & 80,400 & 18.02 & 4.74 & 1.14 & 5.28 \\
\hline 2002 & 6.200 & 84,900 & 18.46 & 5.78 & 2.60 & 4.93 \\
\hline 2003 & 6.200 & 87,000 & 18.60 & 5.99 & 1.93 & 3.33 \\
\hline 2004 & 6.200 & 87,900 & 18.48 & 5.54 & 2.97 & 4.73 \\
\hline 2005 & 6.200 & 90,000 & 18.51 & 5.08 & 3.99 & 4.00 \\
\hline 2006 & 6.200 & 94,200 & 18.02 & 4.61 & 2.08 & 5.11 \\
\hline 2007 & 6.200 & 97,500 & 18.08 & 4.62 & 4.28 & 5.10 \\
\hline 2008 & 6.200 & 102,000 & 17.66 & 5.80 & 0.03 & 4.10 \\
\hline 2009 & 6.200 & 106,800 & 18.34 & 9.28 & 2.63 & 3.72 \\
\hline 2010 & 6.200 & 106,800 & 18.54 & 9.63 & 1.63 & 3.20 \\
\hline 2011 & 6.200 & 106,800 & 18.23 & 8.95 & 2.93 & 3.00 \\
\hline
\end{tabular}


Table 3. Estimated Parameters

\begin{tabular}{|l|l|l|l|}
\hline Parameter & Descriptions & Coefficient & Standard Deviation \\
\hline$\gamma$ & Coefficient of relative risk aversion & 3.393 & 0.148 \\
\hline$v$ & Consumption weight & 0.600 & 0.416 \\
\hline $\mathrm{L}$ & Leisure endowment & 3426.593 & 0.103 \\
\hline$\theta_{p}$ & Fixed cost of work, in hours & 272.638 & 0.318 \\
\hline$\phi$ & Hours of leisure lost, poor health & 311.164 & 0.124 \\
\hline
\end{tabular}

Table 4. Actual and Simulated Distribution of Social Security Benefit Take-up

\begin{tabular}{|l|l|l|l|}
\hline Age & Actual & Simulation (DB pension) & Simulation (DC pension) \\
\hline 62 & 0.351925 & 0.551 & 0.653 \\
\hline 63 & 0.173665 & 0.074 & 0.081 \\
\hline 64 & 0.132776 & 0.092 & 0.071 \\
\hline 65 & 0.309014 & 0.263 & 0.182 \\
\hline 66 & 0.018837 & 0.009 & 0.005 \\
\hline 67 & 0.013783 & 0.010 & 0.008 \\
\hline
\end{tabular}


Table 5. The Effect of the Delayed Retirement Credit on the Social Security Benefit Claiming Distribution

(Birth cohorts 1933 and 1943)

\begin{tabular}{|l|l|l|l|l|l|l|}
\hline Age & \multicolumn{2}{l|}{ Cohort 1933 (DB pension) } & \multicolumn{4}{l|}{ Cohort 1933 (DC pension) } \\
\hline & DRC=3\% & DRC=5.5\% & Difference & DRC $=3 \%$ & DRC=5.5\% & Difference \\
\hline 62 & 0.549 & 0.549 & 0 & 0.629 & 0.628 & -0.001 \\
\hline 63 & 0.057 & 0.057 & 0 & 0.081 & 0.083 & 0.002 \\
\hline 64 & 0.096 & 0.095 & -0.001 & 0.081 & 0.079 & -0.002 \\
\hline 65 & 0.266 & 0.265 & -0.001 & 0.19 & 0.185 & -0.005 \\
\hline 66 & 0.018 & 0.011 & -0.007 & 0.01 & 0.011 & 0.001 \\
\hline 67 & 0.004 & 0.005 & 0.001 & 0.004 & 0.007 & 0.003 \\
\hline 68 & 0.003 & 0.008 & 0.005 & 0.002 & 0.003 & 0.001 \\
\hline 69 & 0.006 & 0.008 & 0.002 & 0.003 & 0.003 & 0 \\
\hline 70 & 0.001 & 0.001 & 0 & 0.001 & 0.001 & 0 \\
\hline & Cohort 1943 (DB pension) & Cohort 1943 (DC pension) & \\
\hline & DRC=3\% & DRC=8\% & Difference & DRC=3\% & DRC=8\% & Difference \\
\hline 62 & 0.497 & 0.497 & 0 & 0.625 & 0.623 & -0.002 \\
\hline 63 & 0.123 & 0.12 & -0.003 & 0.09 & 0.09 & 0 \\
\hline 64 & 0.08 & 0.081 & 0.001 & 0.077 & 0.077 & 0 \\
\hline 65 & 0.261 & 0.255 & -0.006 & 0.193 & 0.177 & -0.016 \\
\hline 66 & 0.024 & 0.018 & -0.006 & 0.007 & 0.02 & 0.013 \\
\hline 67 & 0.005 & 0.015 & 0.01 & 0.003 & 0.005 & 0.002 \\
\hline 68 & 0.001 & 0.004 & 0.003 & 0.002 & 0.003 & 0.001 \\
\hline 69 & 0.000 & 0.008 & 0.008 & 0.003 & 0.002 & -0.001 \\
\hline 70 & 0.001 & 0.001 & 0 & 0.002 & 0.003 & 0.001 \\
\hline
\end{tabular}

Table 6. The Effect of Raising the Full Retirement Age (FRA) on Annual Hours Worked (Birth cohort 1943)

\begin{tabular}{|l|l|l|l|l|l|l|}
\hline Age & \multicolumn{2}{l}{ Cohort 1943 (DB pension) } & \multicolumn{4}{l|}{ Cohort 1943 (DC pension) } \\
\hline & FRA=65 & FRA=66 & Increase & FRA=65 & FRA=66 & Increase \\
\hline 62 & 854.414 & 868.071 & 13.657 & 1099.142 & 1100.175 & 1.033 \\
\hline 63 & 570.064 & 607.554 & 37.49 & 940.422 & 964.725 & 24.303 \\
\hline 64 & 460.591 & 503.256 & 42.665 & 829.306 & 858.711 & 29.405 \\
\hline 65 & 500.961 & 577.21 & 76.249 & 876.766 & 909.886 & 33.12 \\
\hline 66 & 423.468 & 448.191 & 24.723 & 781.454 & 799.605 & 18.151 \\
\hline 67 & 390.247 & 388.868 & -1.379 & 795.791 & 789.768 & -6.023 \\
\hline 68 & 379.344 & 381.985 & 2.641 & 751.327 & 749.773 & -1.554 \\
\hline 69 & 382.615 & 386.432 & 3.817 & 748.318 & 751.632 & 3.314 \\
\hline 70 & 362.615 & 369.85 & 7.235 & 605.79 & 606.85 & 1.06 \\
\hline
\end{tabular}


Figure 1-A. Trends in the Labor Force Participation Rate, Older Men (Source: Current Population Survey)

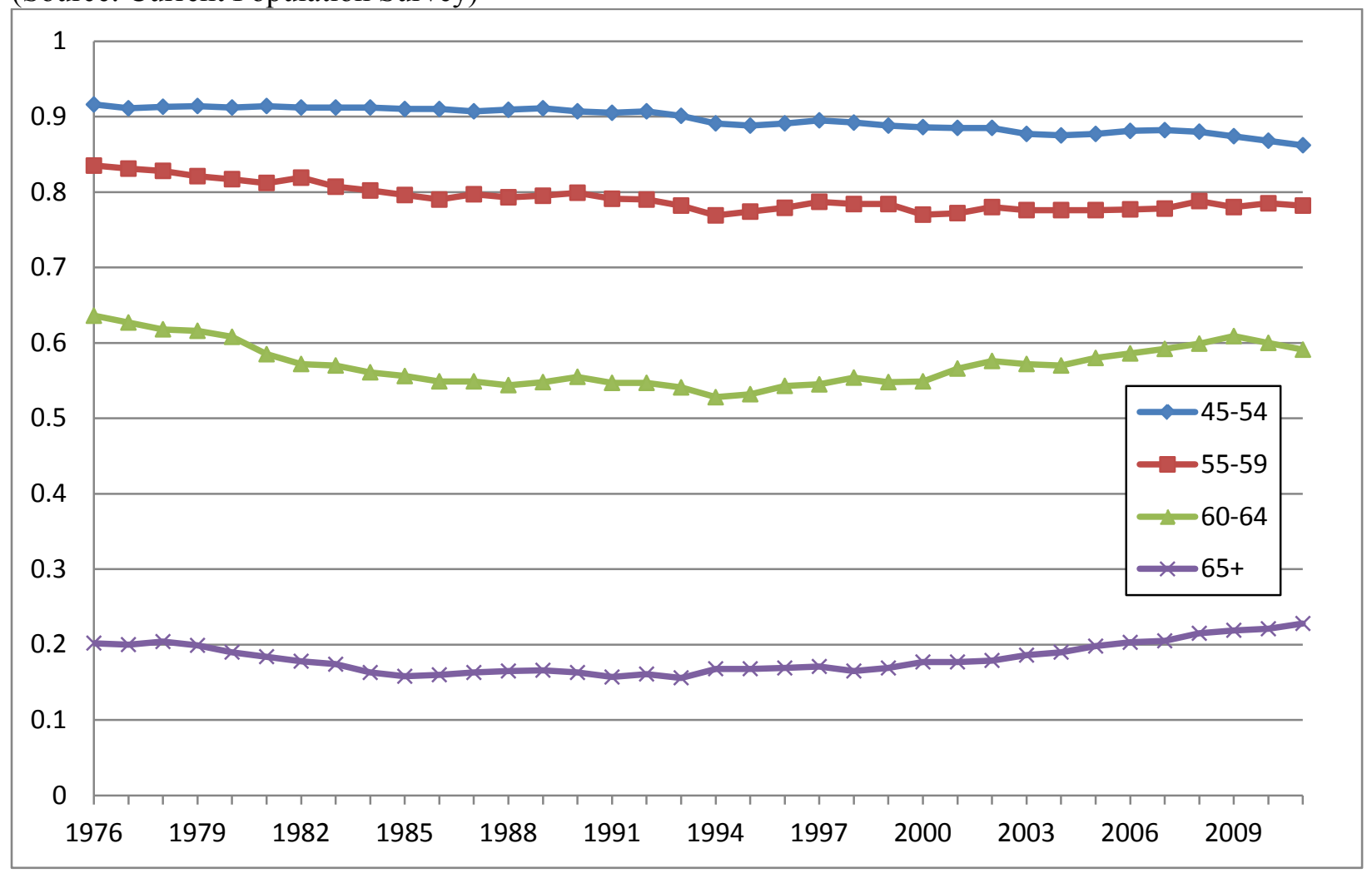

Figure 1-B. Trends in the Labor Force Participation Rate, Older Women (Source: Current Population Survey)

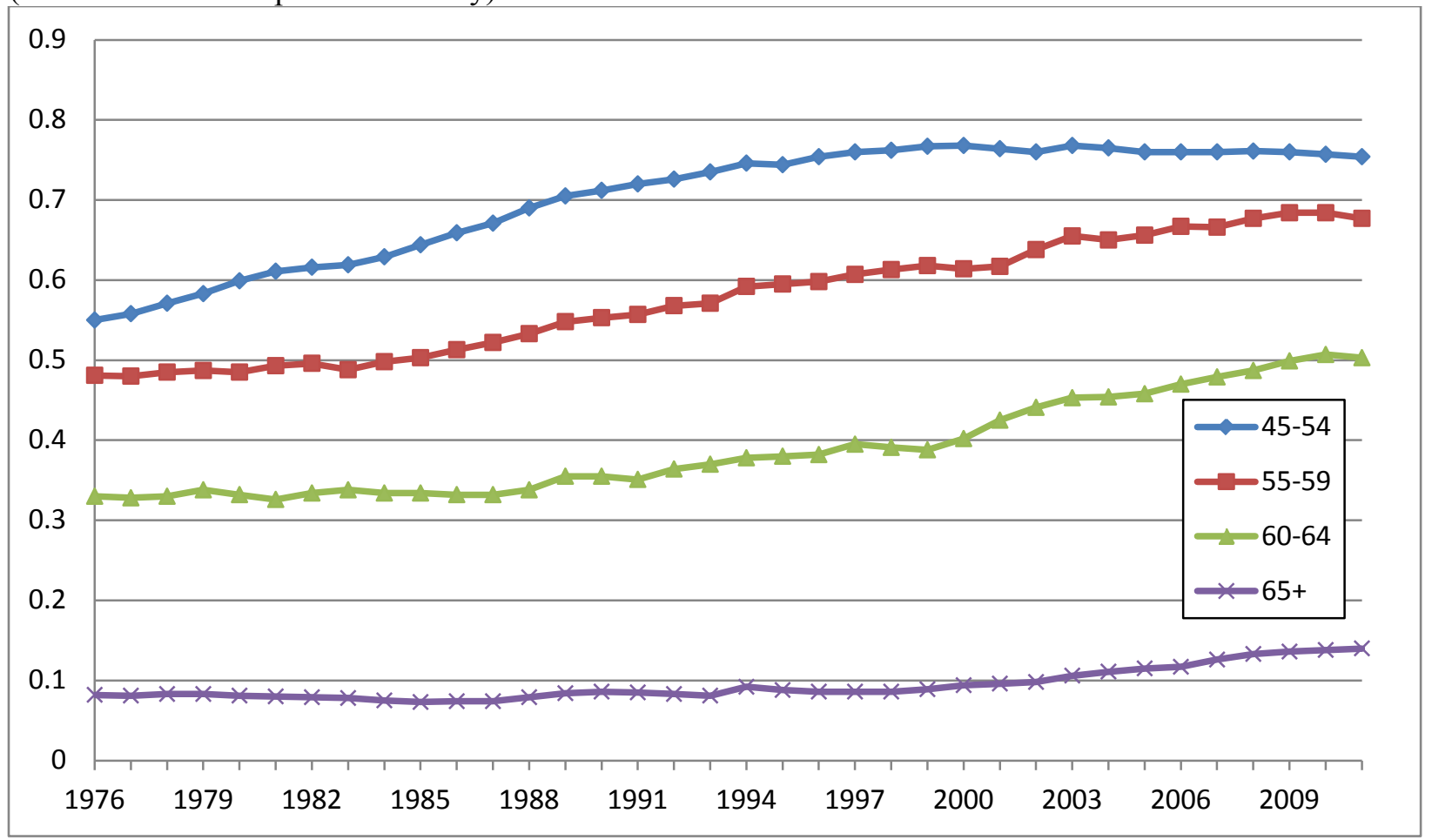


Figure 2. Pension Coverage by Pension Type, Men and Women

(Source: Survey of Consumer Finances, various waves 1992-2007)

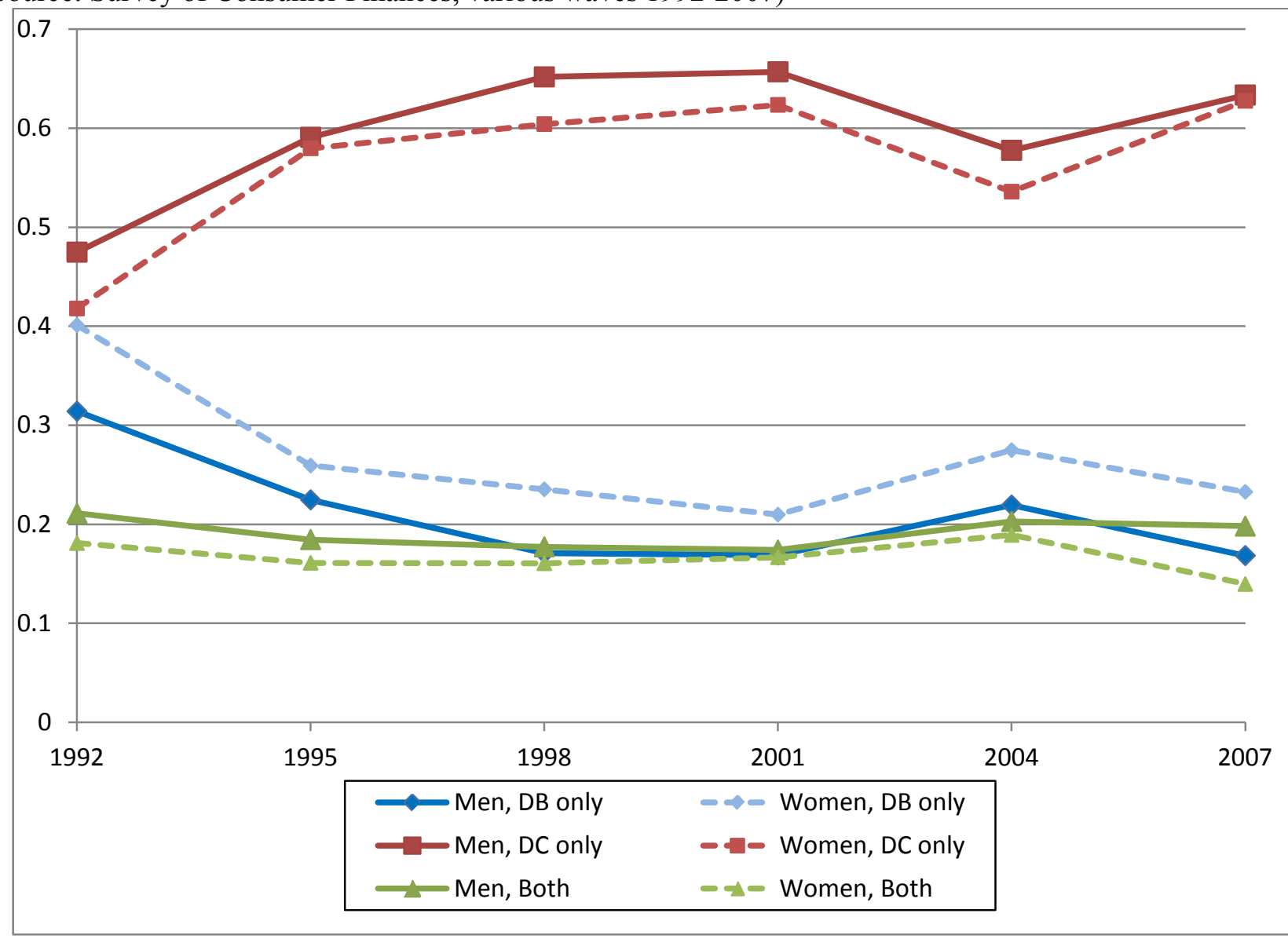


Figure 3. Pension with Current Employment (ages 50-59), Birth Cohorts 1911-1959

(Source: SIPP, various waves 1984-2009)

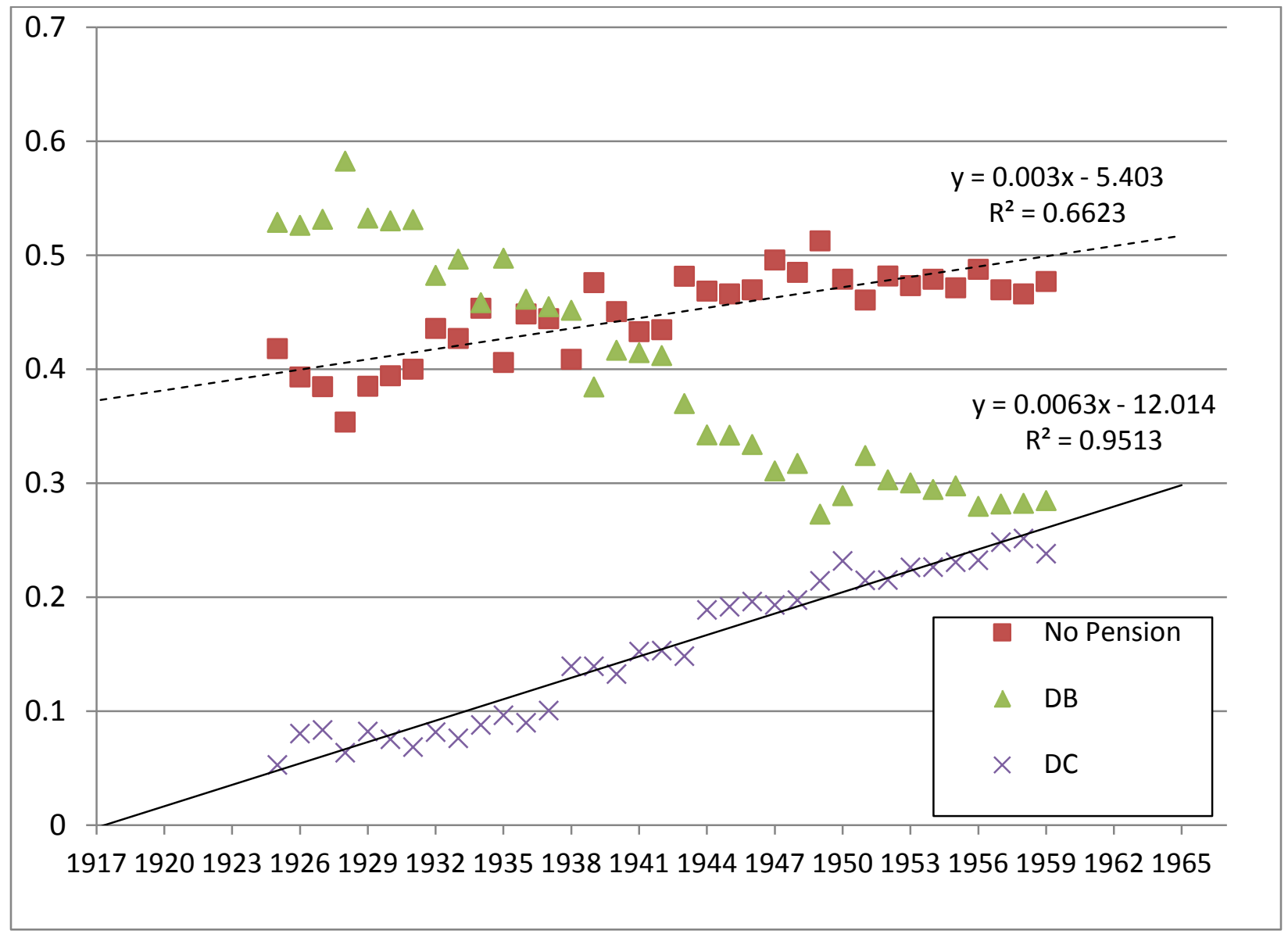


Figure 4. Claiming Age Distribution, Birth Cohorts 1911-1937

(Source: Master Beneficiary Records 2001, 2004)

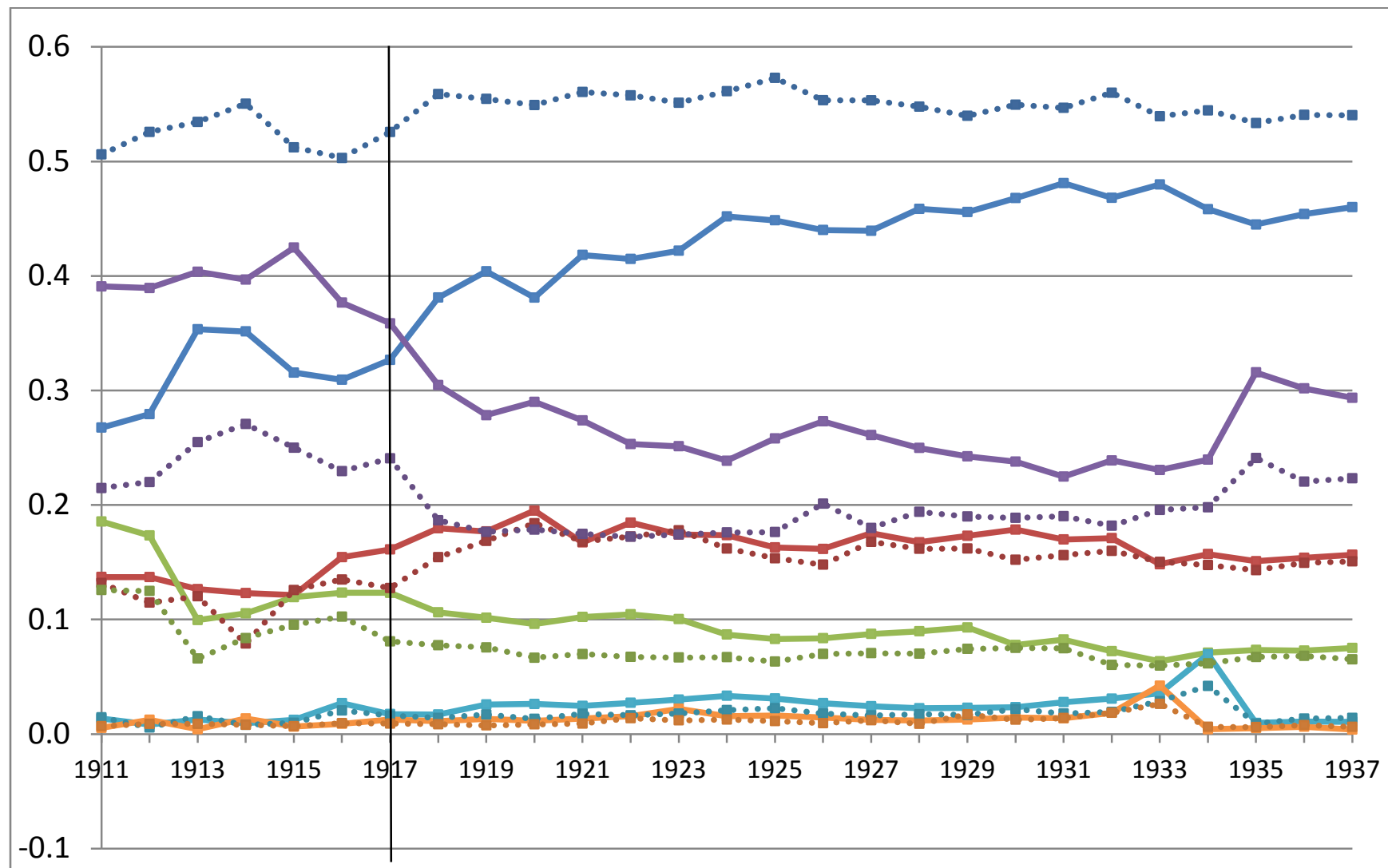

\begin{tabular}{|c|c|c|}
\hline$\Longrightarrow$ Age 62 - Men & $\Longrightarrow$ Age 63 - Men & $\Longrightarrow$ Age 64 - Men \\
\hline$=$ Age 65 - Men & $=$ Age 66 - Men & $=$ Age 67 - Men \\
\hline .... Age 62 - Women & .... Age 63 - Women & ..... Age 64 - Women \\
\hline … Age 65 - Women & … Age 66 - Women & ..... Age 67 - Women \\
\hline
\end{tabular}


Figure 5. Annual Hours Worked by Pension Type (DB vs. DC), Ages 59-70

(Source: Life cycle simulation based on 1917 birth cohort)

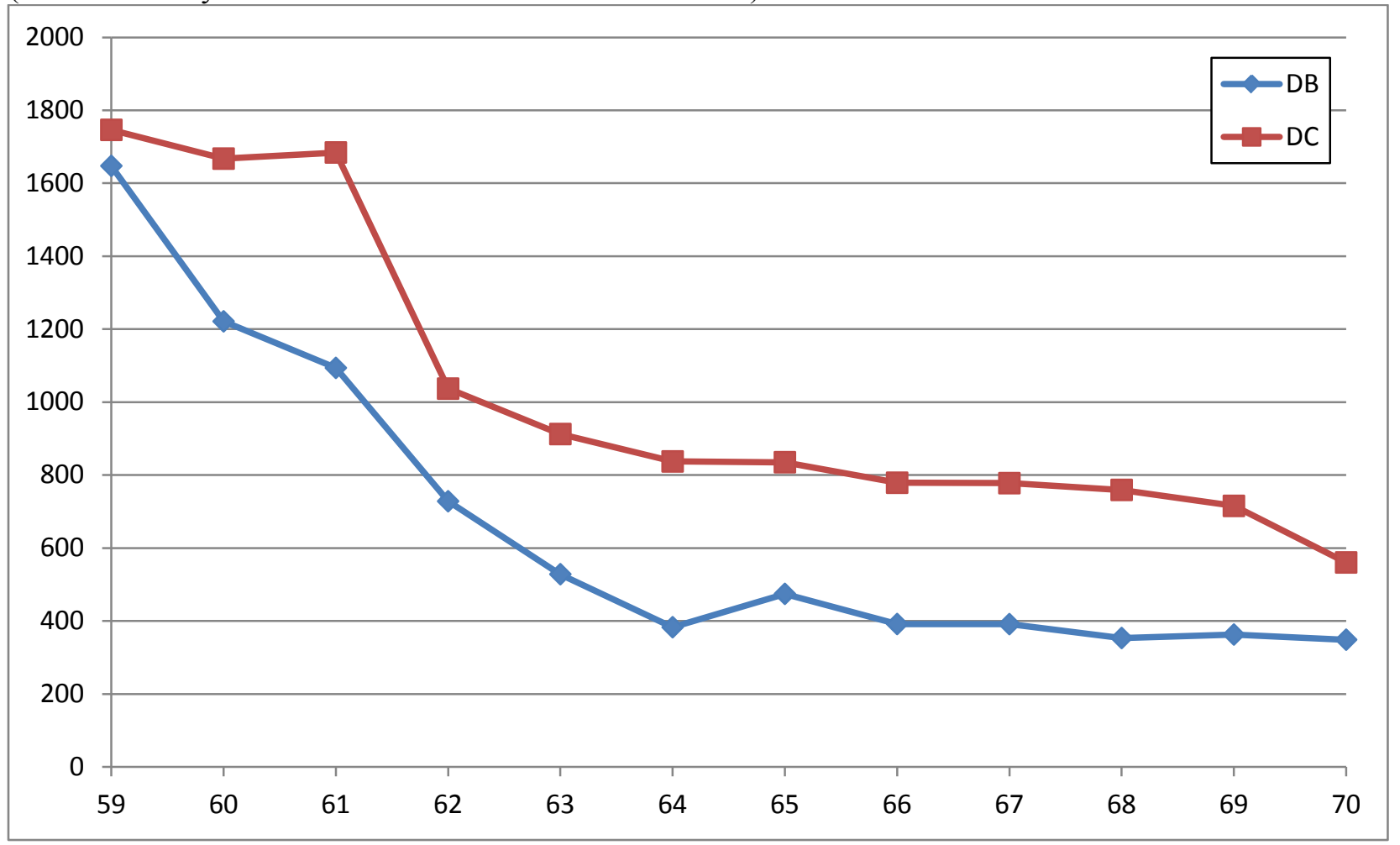

Figure 6. Labor Force Participation by Pension Type (DB vs. DC), Ages 59-70

(Source: Life cycle simulation based on 1917 birth cohort)

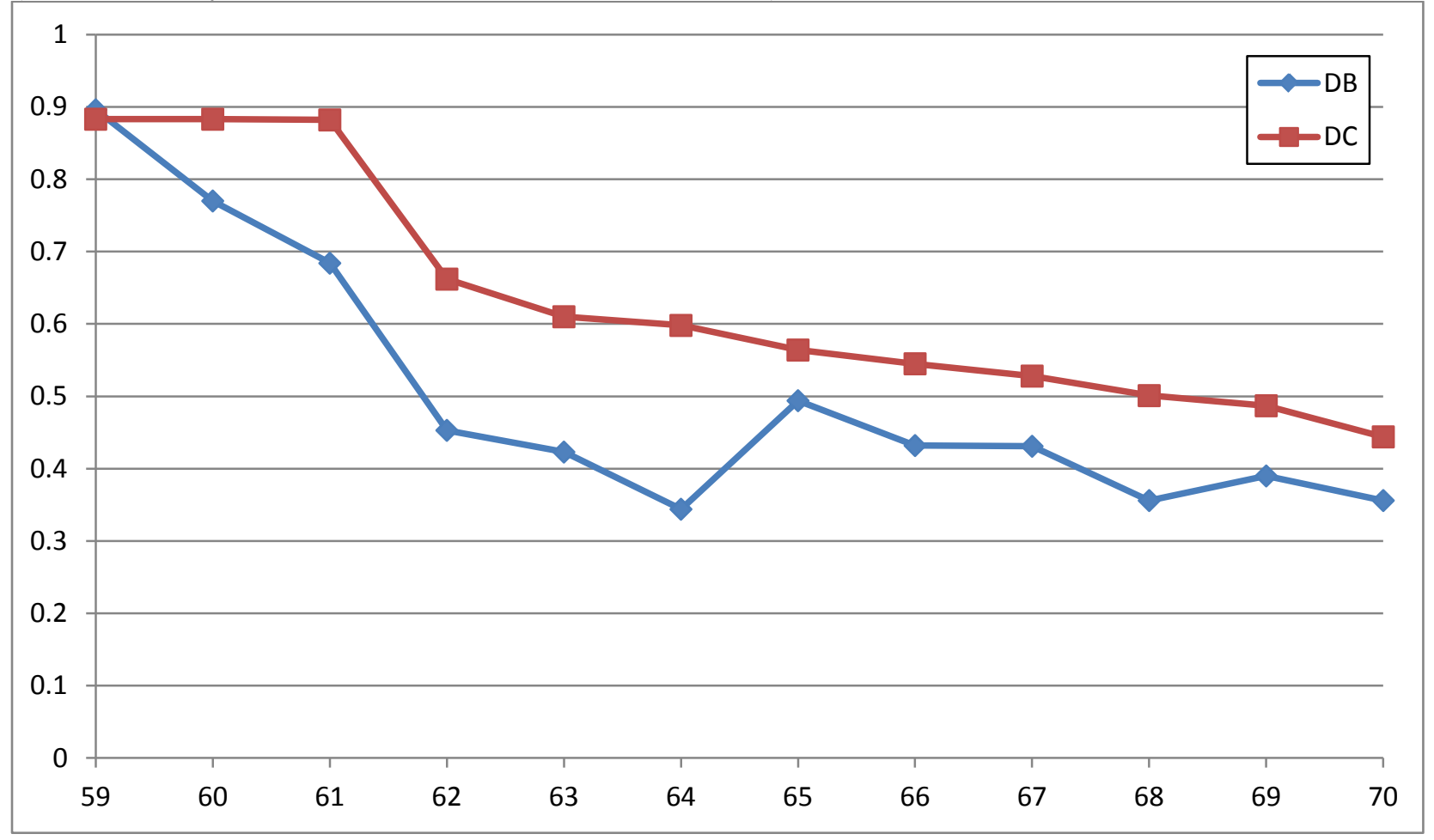


Figure 7. Labor Force Participation by Age Group (all pension states: "DB," "DC," and "No Plan") (Source: Comprehensive cohort simulation)

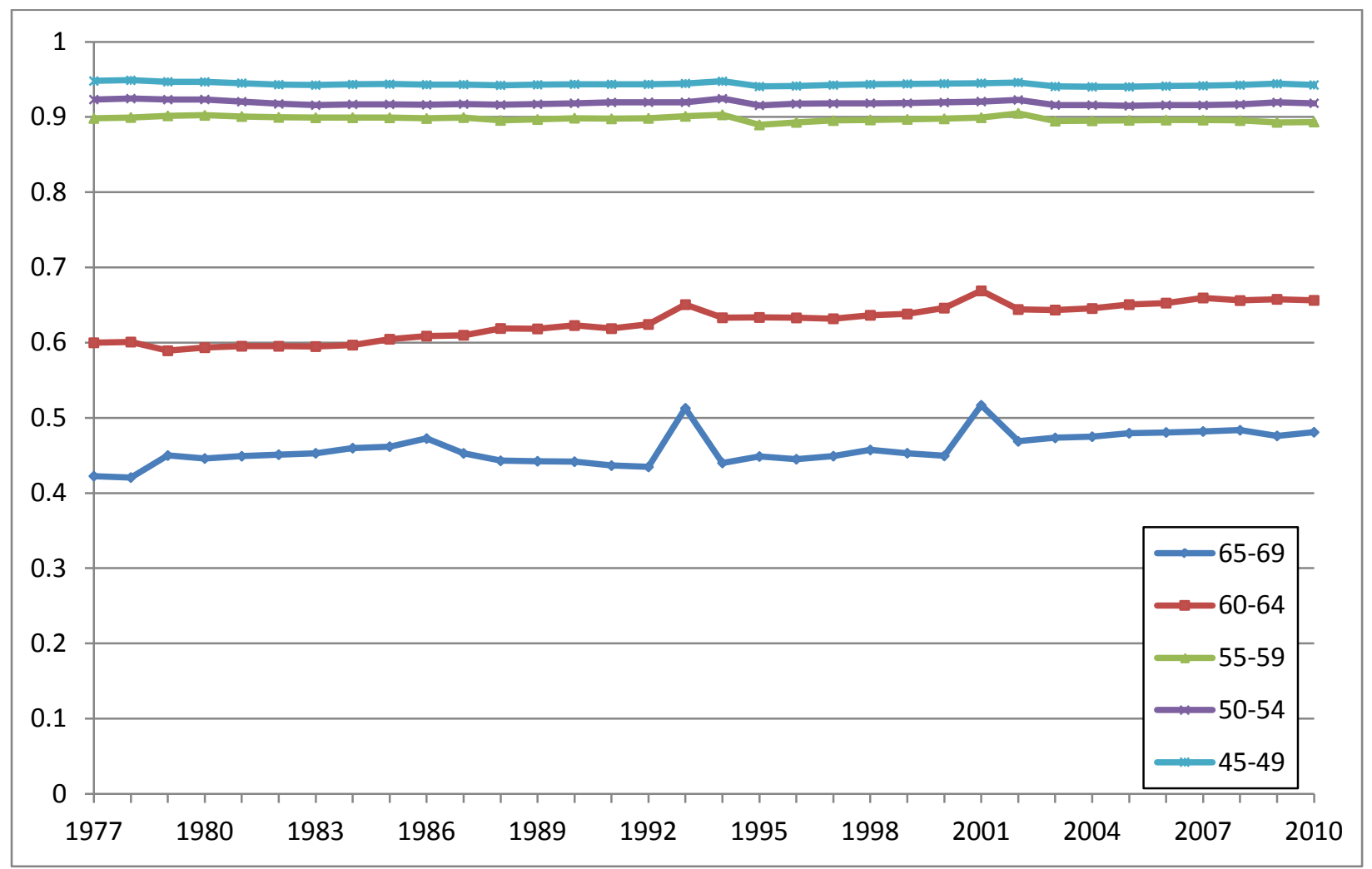

Figure 8. Labor Force Participation by Age Group (states: "DB” and "No Plan" only) (Source: Comprehensive cohort simulation)

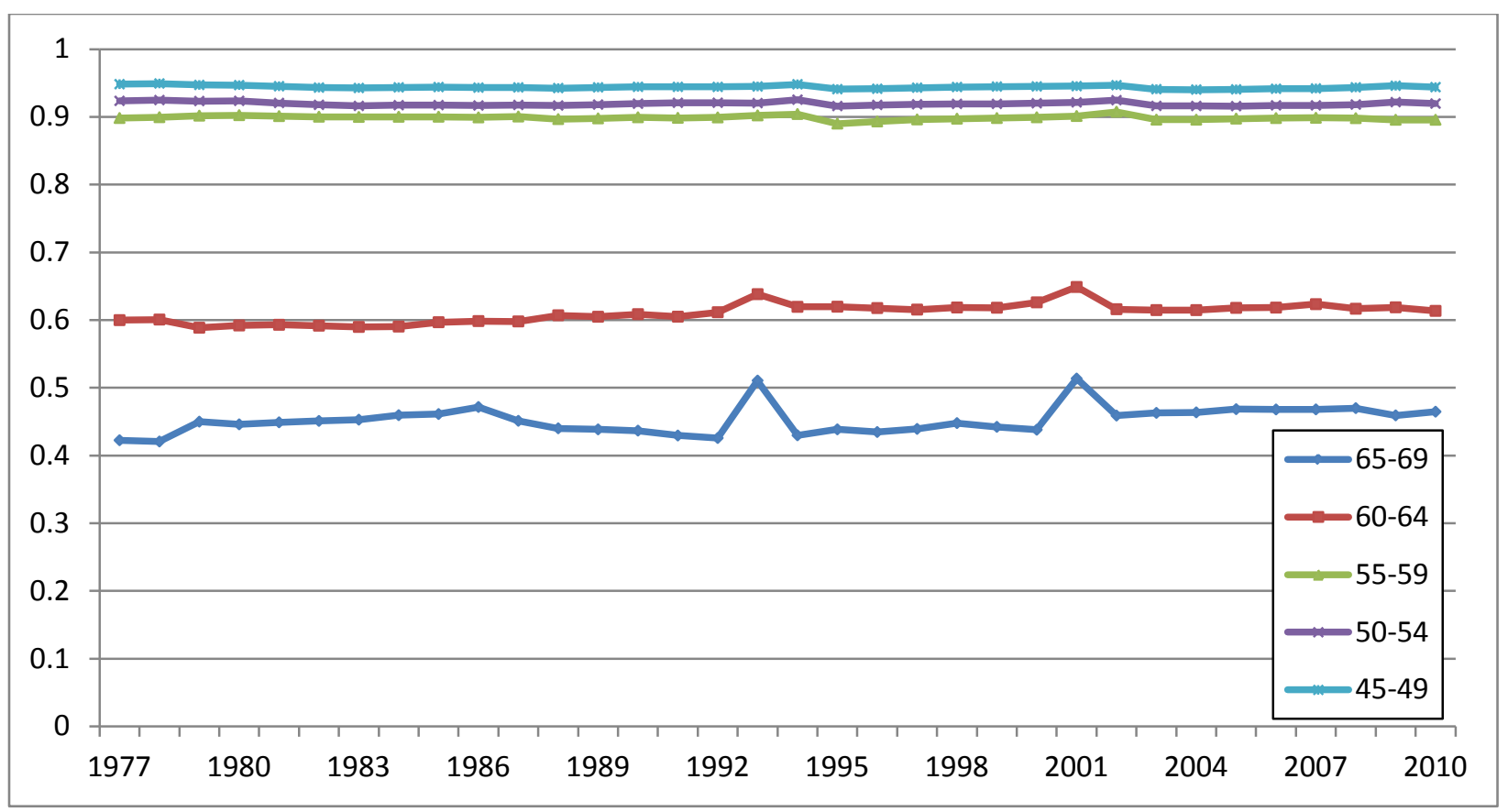


Figure 9. Labor Force Participation by Pension Structure, Age 60-64, 65-69

(Source: Comprehensive cohort simulation)

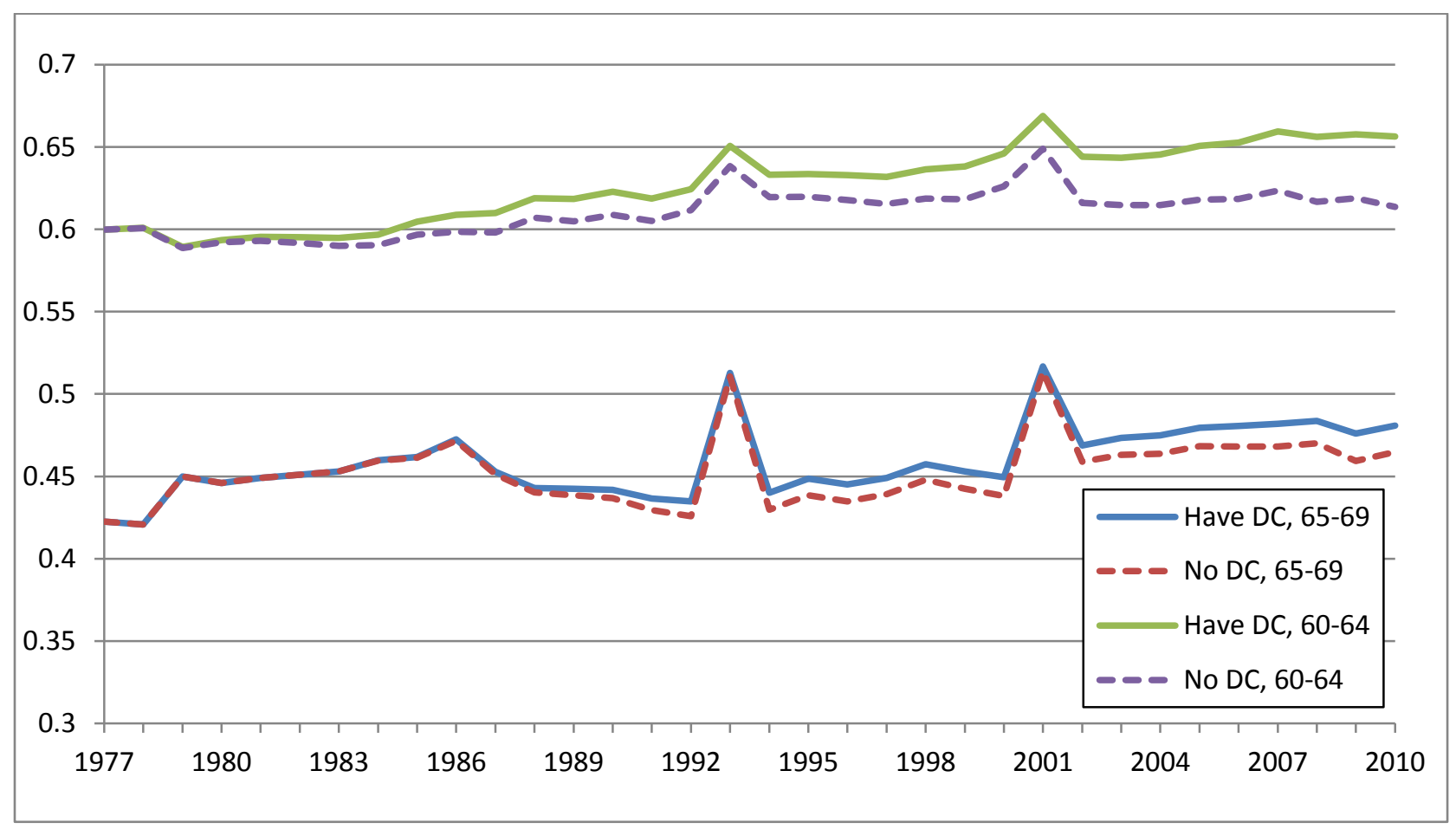


Figure 10. Labor Force Participation by Pension Structure, Age 45-49, 50-54, 55-59

(Source: Comprehensive cohort simulation)

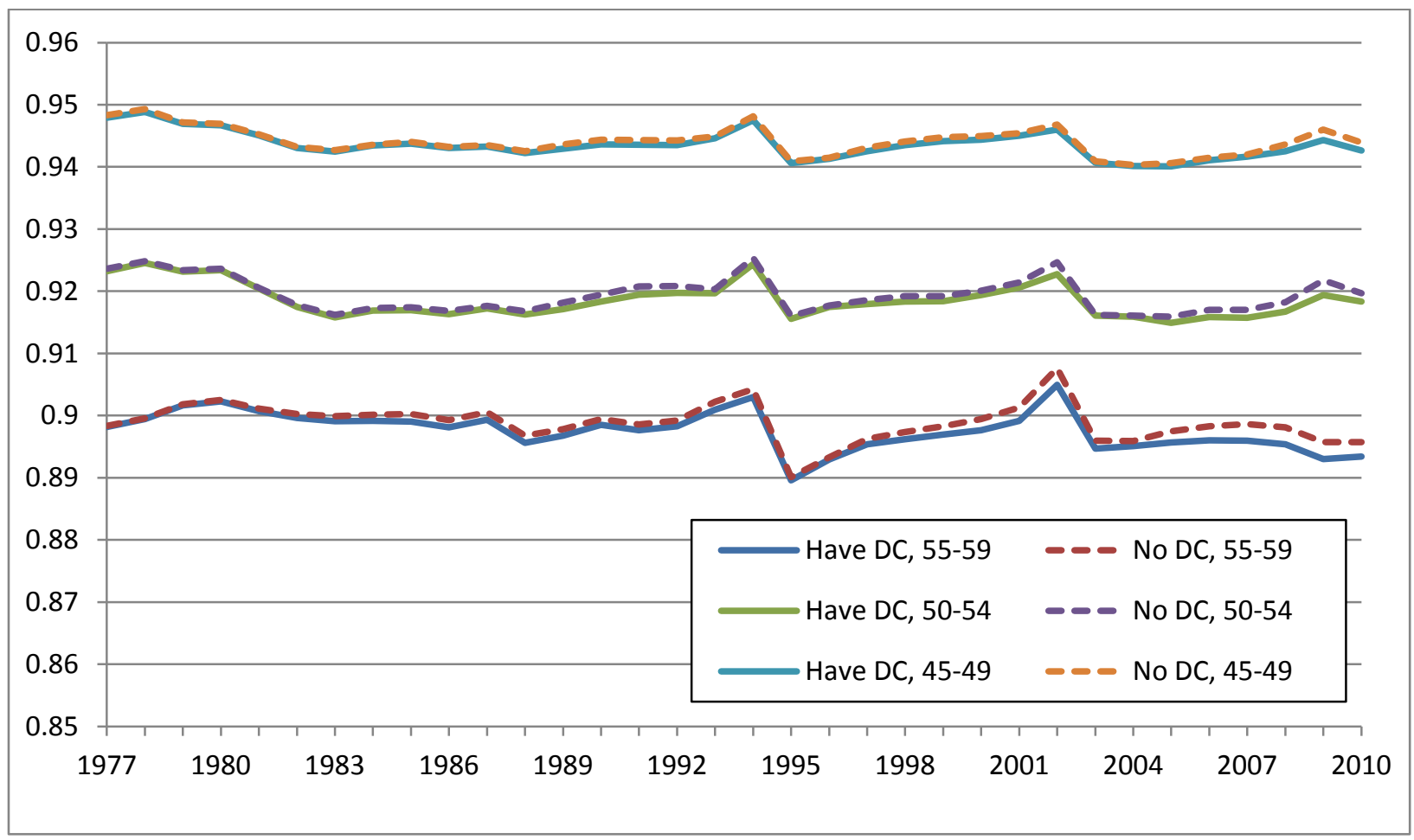

Figure 11. Predicted Labor Force Participation Rates, Age 55-59, 60-64, 65-69

(Source: Comprehensive cohort simulation)

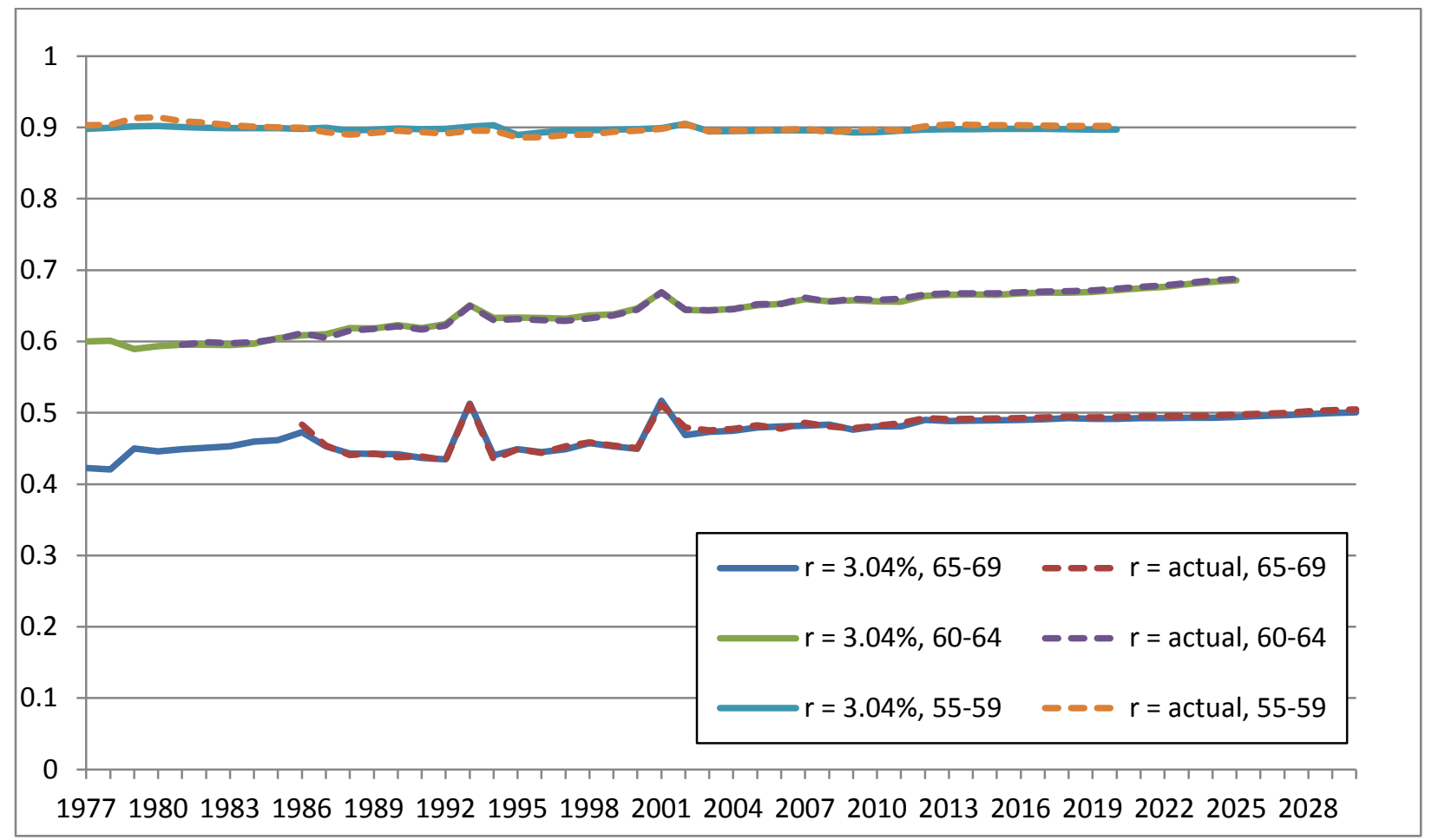


Figure 12. Effect of Increasing FRA on Benefit Claiming Distribution, Cohort 1943 (DB only) (Source: Life cycle simulation)

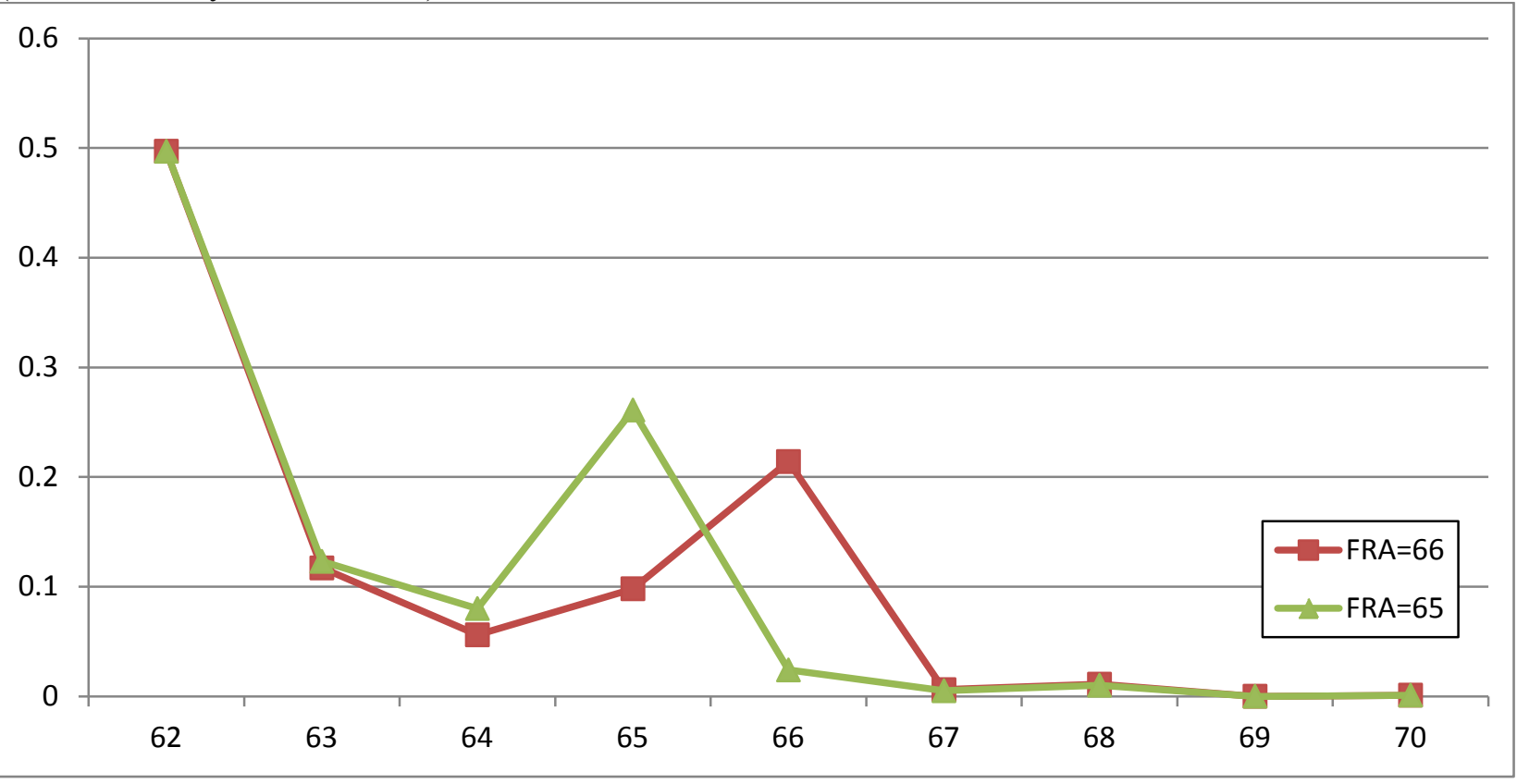

Figure 13. Effect of Increasing FRA on Benefit Claiming Distribution, Cohort 1943 (DC only) (Source: Life cycle simulation)

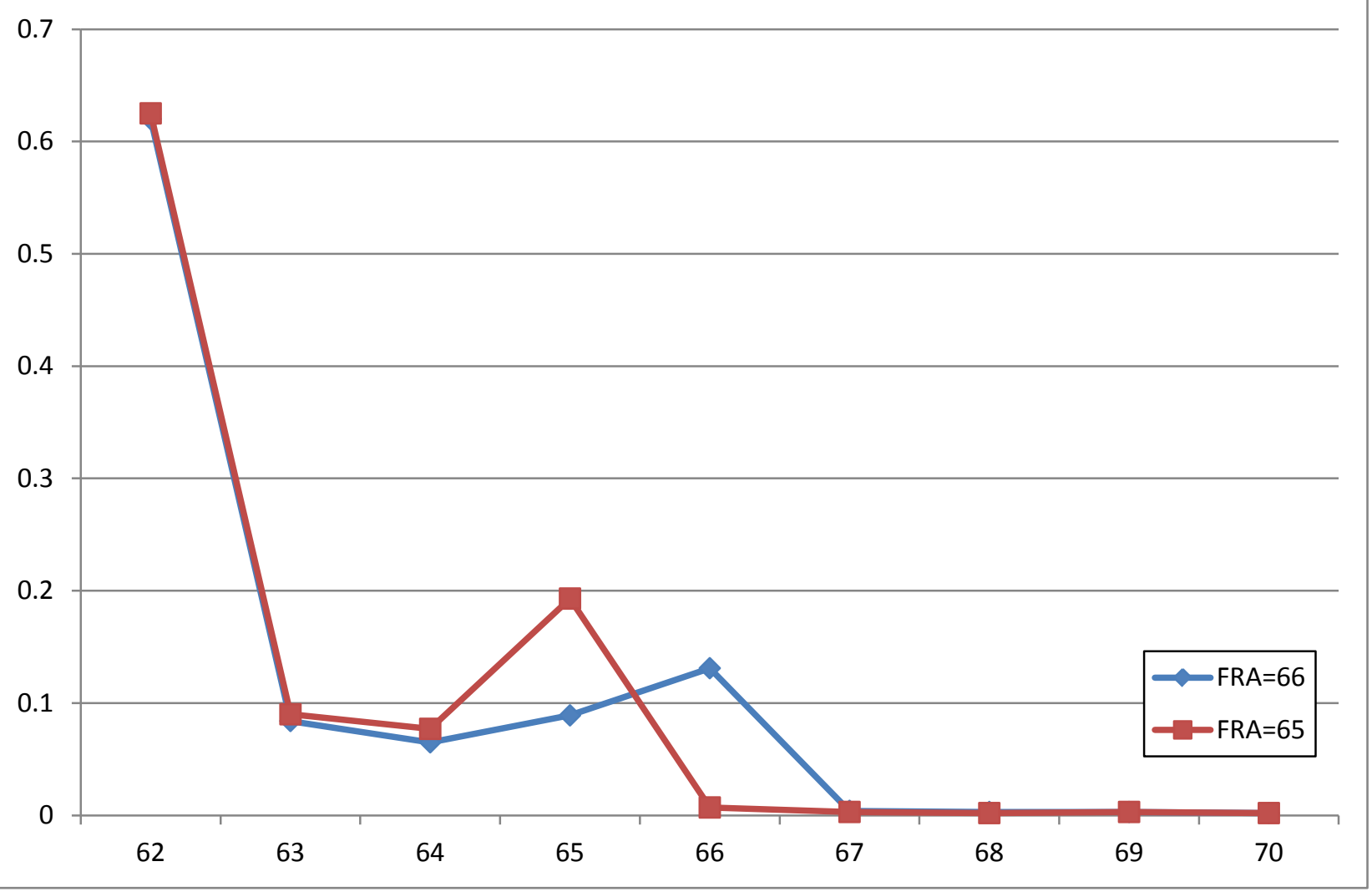




\section{FIGURES APPENDIX}

Figure A-1. Simulated Annual Hours Worked by Pension Plan (Cohort 1917, Age 25-65)

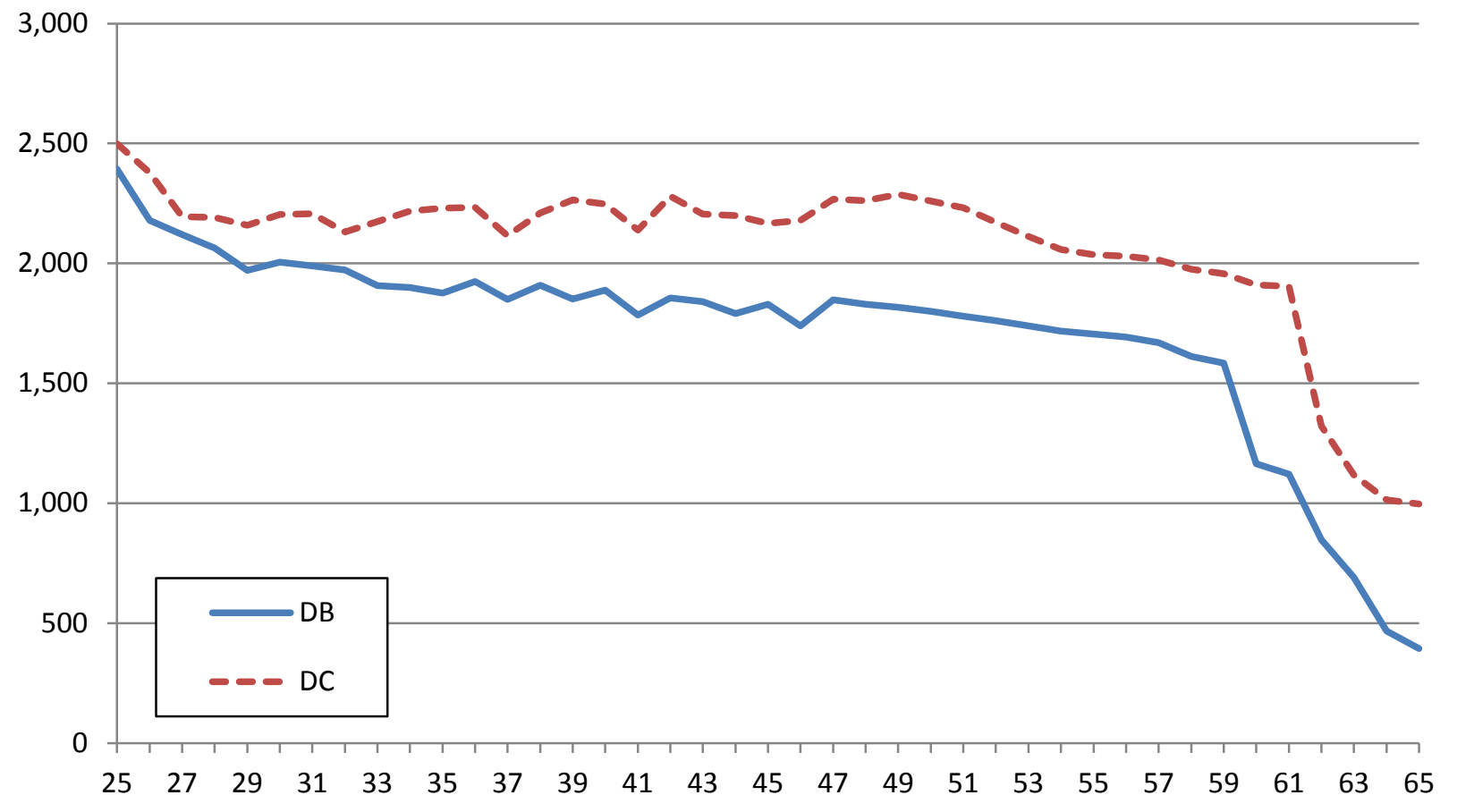

Figure A-2 Simulated Average Hourly Wage by Pension Plan (Cohort 1917, 2011 dollars, Age 25-65)

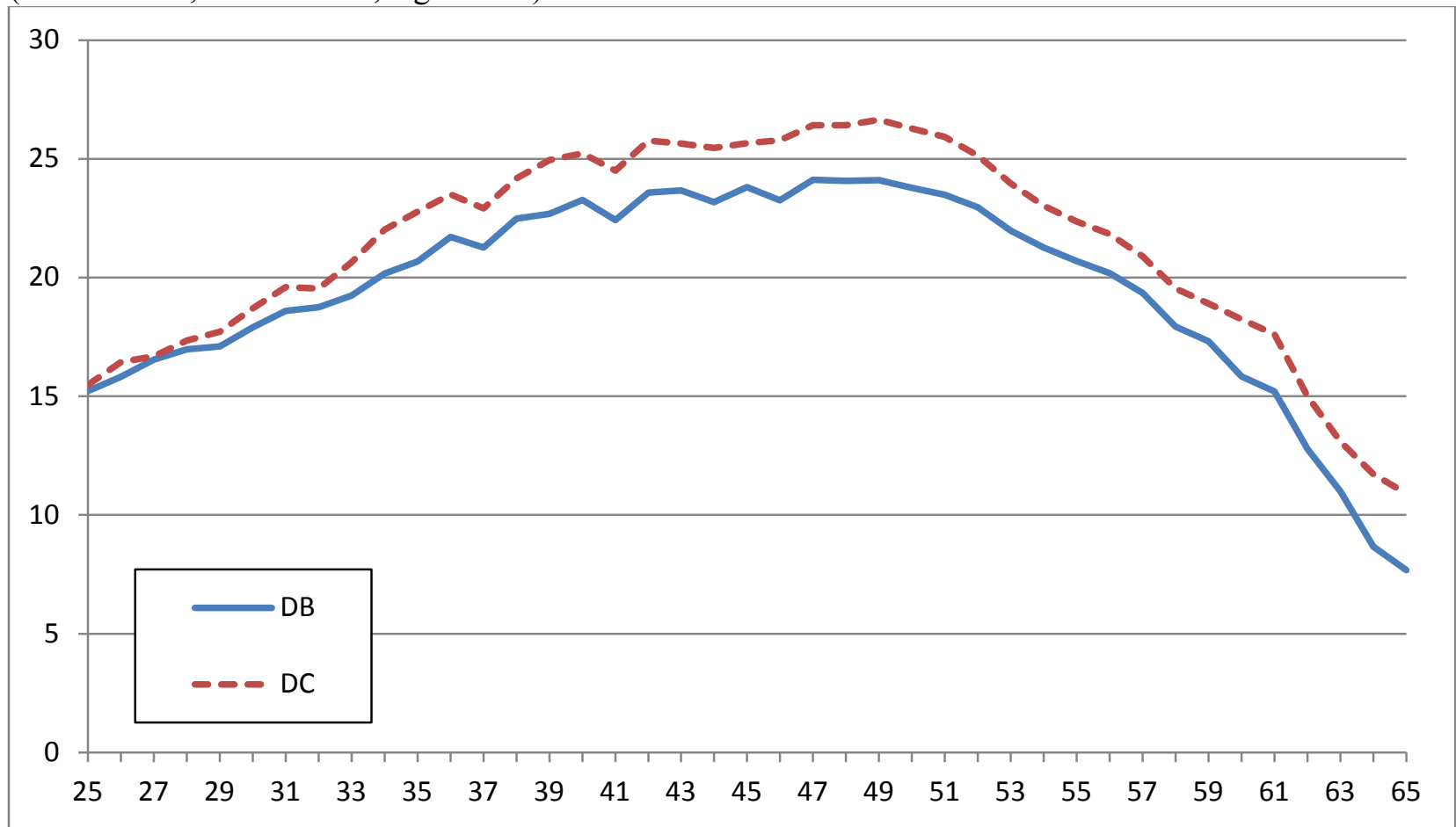


Figure A-3 Simulated Consumption by Pension Plan (Cohort 1917, 2011 dollars, Age 25-65)

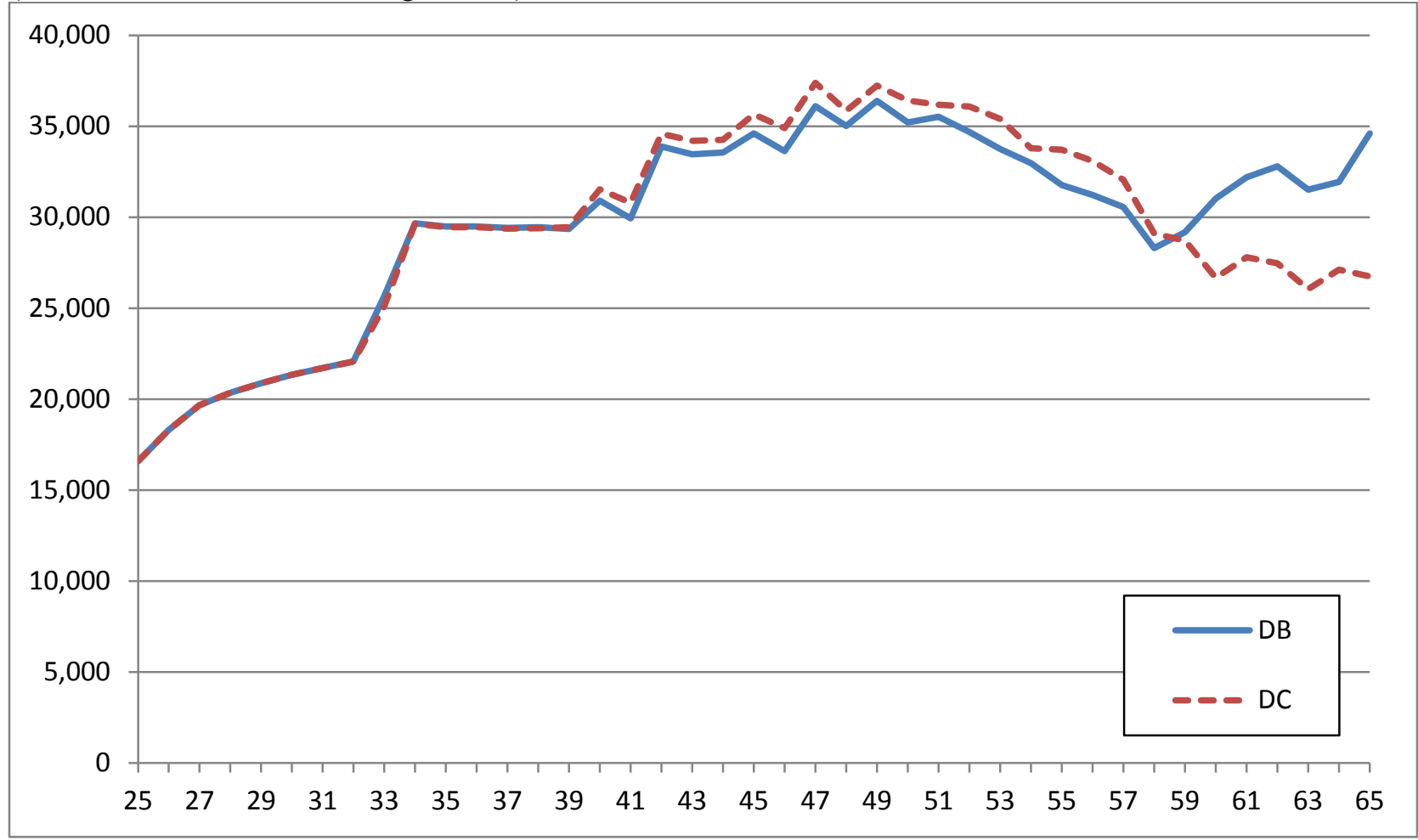

Figure A-4 Simulated Average Assets by Pension Plan (Cohort 1917, 2011 dollars, Age 25-65)

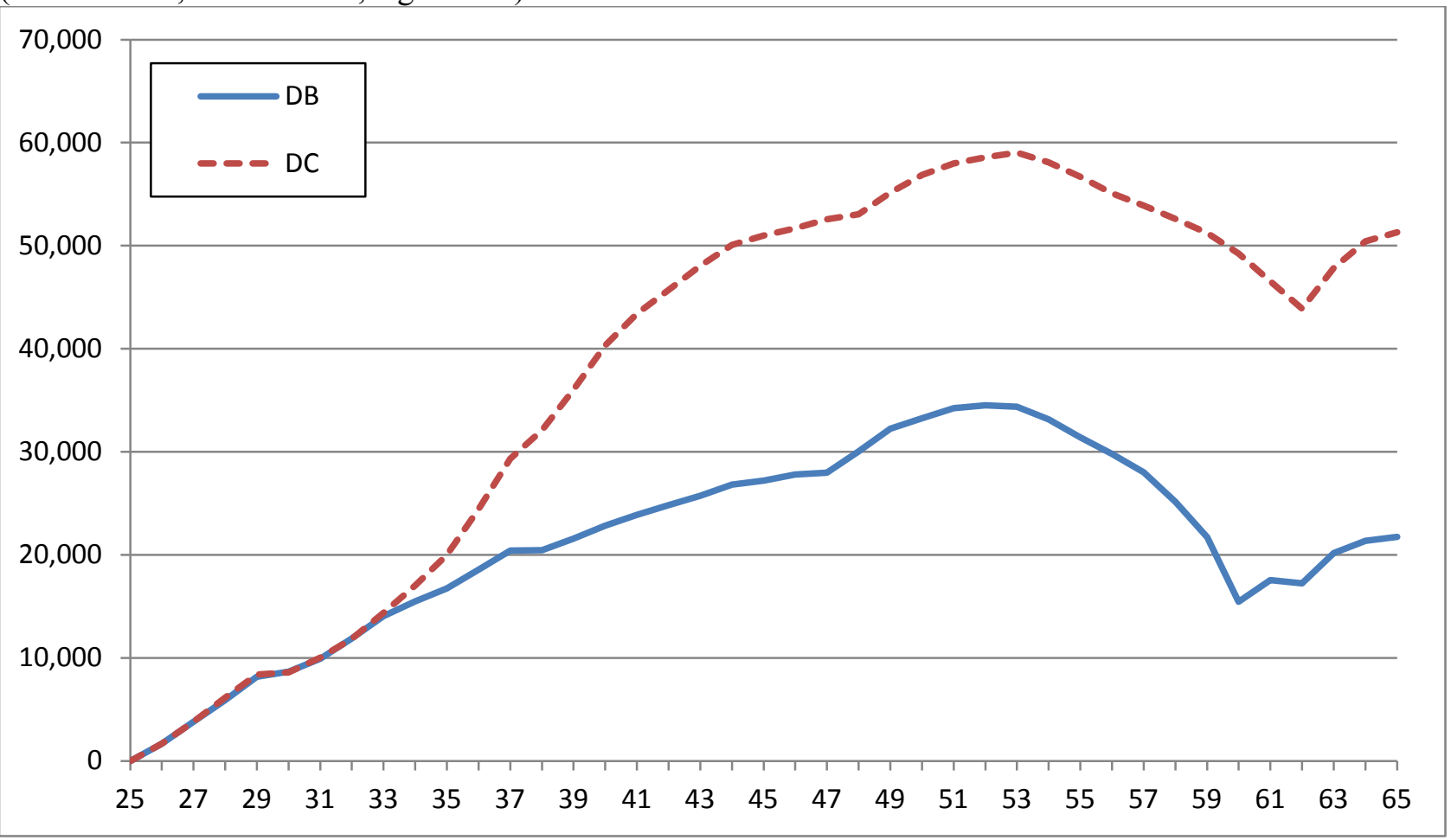




\section{RECENT WORKING PAPERS FROM THE CENTER FOR RETIREMENT RESEARCH AT BOSTON COLLEGE}

How Would GASB Proposals Affect State and Local Pension Reporting?

Alicia H. Munnell, Jean-Pierre Aubry, Joshua Hurwitz and Laura Quinby, June 2012

Borrow Less Tomorrow: Behavioral Approaches to Debt Reduction

Dean Karlan and Jonathan Zinman, May 2012

Spousal Labor Market Effects from Government Health Insurance: Evidence from A Veterans Affairs Expansion

Melissa A. Boyle and Joanna N. Lahey, April 2012

Measuring Social Security Proposals by More than Solvency: Impacts on Poverty, Progressivity, Horizontal Equity, and Work Incentives

Melissa M. Favreault and C. Eugene Steuerle, April 2012

How Important Is Asset Allocation to Financial Security in Retirement?

Alicia H. Munnell, Natalia Sergeyevna Orlova, and Anthony Webb, April 2012

Great Recession-Induced Early Claimers: Who Are They? How Much Do They Lose?

Matthew S. Rutledge and Norma B. Coe, April 2012

Effects of Employer Health Costs on the Trend and Distribution of Social Security-Taxable Wages

Gary Burtless And Sveta Milusheva, April 2012

Should Households Base Asset Decumulation Strategies on Required Minimum Distribution Tables?

Wei Sun and Anthony Webb, April 2012

Geographic Mobility Among Residents in Seniors Housing and Care Communities:

Evidence from the Residents Financial Survey

Norma B. Coe and April Yanyuan Wu, April 2012

Costs and Concerns among Residents in Seniors Housing and Care Communities: Evidence from the Residents Financial Survey

Norma B. Coe and April Yanyuan Wu, April 2012

Financial Well-Being of Residents in Seniors Housing and Care Communities: Evidence from the Residents Financial Survey

Norma B. Coe and April Yanyuan Wu, April 2012

All working papers are available on the Center for Retirement Research website (http://crr.bc.edu) and can be requested by e-mail (crr@bc.edu) or phone (617-552-1762). 